\title{
Sobre el Derecho constitucional y sus fundamentos (III). El constitucionalismo de los derechos e interpretación de la Constitución
}

\author{
Miguel Revenga Sánchez ${ }^{1}$ \\ Universidad de Cádiz - España
}

Revista Derechos en Acción ISSN 2525-1678/ e-ISSN 2525-1686

Año 5/N 14 , Verano 2019-2020 (21 diciembre a 20 marzo), 27-78

DOl: https://doi.org/10.24215/25251678e355

ORCID: https://orcid.org/0000-0002-7807-6684

Recibido: 01/07/2019

Aprobado: 01/08/2019

Resumen: En un trabajo sobre los fundamentos del derecho constitucional, rescatando las bases históricas de la constitución y el constitucionalismo el autor plantea que en la enseñanza y estudio de la materia el constitucionalista debe esforzarse por atraer la atención del alumno acerca los siguientes extremos; a ) Cuál es el significado de la Constitución como norma política en la que se encuentra el agregado de ideas y concepciones que permite fundamentar un orden de convivencia democrática. b) Qué es lo que diferencia, formal y materialmente, a la Constitución del resto de las normas que integran el ordenamiento jurídico y, last but not least, y c) Cuáles son las técnicas mediante las cuales se persigue el influjo que la Constitución debería ejercer sobre el ordenamiento jurídico en su dinámica de funcionamiento efectivo.

Palabras clave: Constitución. Derecho Constitucional. Enseñanza.

Abstract: In a work about the foundations of constitutional law, rescuing the historical basis of the constitution and constitutionalism, the author

Catedrático de Derecho Constitucional en la Universidad de Cádiz.

E-mail: miguel.revenga@uca.es 
states that in the teaching and study of the subject, the Constitutionalist must make an effort to attract the attention of the student on following: a) What is the meaning of the Constitution as a political norm in which the aggregate of ideas and conceptions of an order of democratic coexistence are present. b) What differentiates, formally and materially, the Constitution from the rest of the norms that integrate the legal system and, last but not least, c) What are the techniques by which the influence that the Constitution should exert is pursued on the legal system, in its dynamics of effective functioning.

Keywords: Constitution. Constitutional right. Teaching.

Resumo: Em um trabalho sobre os fundamentos do direito constitucional, resgatando as bases históricas da constituição e o constitucionalismo, 0 autor afirma que no ensino e estudo da matéria, o constitucionalista deve se esforçar para atrair a atenção do aluno sobre os seguintes extremos: a) Qual é o significado da Constituição como norma política na que está 0 agregado de ideias e concepções que permitem basear uma ordem de convivência democrática. b) 0 que diferencia, formal e materialmente, a Constituição do resto das normas que integram o sistema legal e, last but not least, c) Quais são as técnicas pelas quais o influxo que a Constituição deve exercer sobre o sistema legal em sua dinâmica de funcionamento efetivo é perseguido?

Palavras-chave: Constituição Direito constitucional. Ensino.

Résumé: Dans cet article sur les fondements du droit constitutionnel, qui sauvegarde les bases historiques de la constitution et du constitutionnalisme, l'auteur considère que, dans l'enseignement et l'étude de cette matière, le constitutionnaliste doit s'efforcer d'attirer l'attention de l'élève sur les différents points suivants; a) que signifie la Constitution en tant que norme politique regroupant un ensemble d'idées et de conceptions qui permettent de fonder un ordre de coexistence démocratique? b) qu'est-ce qui différencie, formellement et concrètement, la Constitution du reste des normes qui intègrent le système juridique et, last but not least, c) Quelles sont les techniques à travers lesquelles se poursuit l'influence que la Constitution devrait exercer sur le système juridique dans sa dynamique de fonctionnement effective.

Mot-clés: Constitution Droit constitutionnel. Enseignement. 
摘要:在一部关于宪法基础的工作中, 拯救宪法和宪政的历史基础, 作者指出, 在该学科的教学和研究中, 宪政主义者必须努力吸引学生 关注以下极端； a) 宪法作为一种政治规范的含义是什么, 其中是允 许建立民主共存秩序的思想和概念的总和。b) “宪法”与其他整合法 律体系的规范, 最后但并非最不重要的, 以及c） “宪法”应施加的影 响的技术有何区别, 正式和实质上有何区别关于法律制度的有效运 作动态。

关键字: 关键字: 政治宪法, 宪法, 教学

\section{Tras las cenizas de la guerra, la reconstrucción. El retorno del constitucionalismo}

En un trabajo publicado poco después de la conclusión del juicio de Nuremberg, Herbert Wechsler terminaba su análisis de las decisiones allí adoptadas, rebatiendo el argumento de que el Tribunal formado por los aliados había administrado una justicia de vencedores y, por lo mismo, parcial e imbuida del deseo de aplicar una revancha política. Para el autor de la teoría de los "principios neutrales" en la interpretación del Derecho Constitucional, el juicio de Nuremberg, en mayor medida aún que la Carta de San Francisco, había representado, por el contrario, la asunción solemne de una obligación: la de edificar un sistema de derecho justo, aplicable a todos y con instituciones lo suficientemente fuertes como para llevarlo a efecto. "Si culminamos con éxito esa gran tarea, - concluía Wechsler - y ninguna nación puede hacerlo por sí sola, Nuremberg pasará a la historia como la piedra angular de la casa de la paz. Pero si fracasamos, habremos de escuchar, de boca de la Alemania devastada, que el juicio de Nuremberg ha sido un segundo trágala (diktat) como el de Versalles. Y me temo - añadía - que, no obstante la bondad de nuestras intenciones, nos habremos quedado faltos de respuesta" ${ }^{2}$.

2 Herbert Wechsler, "The Issues of the Nuremberg Trial" (1946), recogido ahora en Principles, Politics and Fundamental Law. Selected Essays, Cambridge, Harvard University Press, 1961, pp. 138 y ss. 
El sistema de derecho justo a escala planetaria, y la disposición de instituciones con efectiva capacidad de asegurar la salvaguarda del mismo, continúa siendo, al paso de los años, la gran utopía pendiente de realización. Pero, quizá por vez primera en la historia, aparecen ante nuestros ojos signos de una racionalidad global que pugna decididamente por avanzar en la única dirección compatible con el logro de dicho ideal utópico. El retorno del constitucionalismo tiene así lugar en condiciones muy distintas a las de la época de las revoluciones burguesas. No en el seno de unidades estatales cerradas y autoreferenciales, con escasa comunicación entre ellas, sino en un universo político comunicado e interdependiente, concienciado sobre su destino, y con posibilidad de expresarse como tal a través de organizaciones que pugnan por ser cada vez más operativas.

El viejo Estado-Nación, surgido en el Renacimiento, está perdiendo, a ojos vista, su condición de referente único de la actividad política; y el constitucionalismo, como ideología de la libertad y emancipación de los seres humanos, afronta nuevos y apasionantes retos. Por lo pronto, el de eludir el riesgo de que lo que ha dado en llamarse ideología de la Constitución sea una mera cobertura en lo ideológico, y una mera formalización en lo jurídico, de un neoliberalismo convertido, tras la caída del muro de Berlín, en el genuino dios constitucional. La globalización no supone "el final de la historia", ni la plasmación del viejo mito redivivo del "reino feliz de los tiempos finales". Muy al contrario, es tarea del constitucionalismo, en la hora presente, reactivar en toda su potencia, y a la luz de la experiencia acumulada, el motor utópico que le impulsó a presentar como "verdades evidentes" los derechos del ser humano y a inscribir en sus señas de identidad el gran tríptico de ideales de la Revolución francesa, libertad-igualdad-fraternidad ${ }^{3}$.

3 Cfr. el trabajo de Peter Häberle, Libertad, igualdad, fraternidad. 1789 como historia, actualidad y futuro del Estado Constitucional, Madrid, Trotta, 1998. Tomo la expresión "ideología de la Constitución", una especie de traslación a nuestro terreno del modelo de "pensamiento 
Si algún elemento común puede encontrarse en el constitucionalismo de la posguerra, tal es, sin lugar a dudas, la reconstrucción de la idea de Constitución en torno a un núcleo representado por la defensa de los derechos fundamentales y el principio democrático frente a la negación de ambos por los regímenes totalitarios del $\mathrm{Eje}^{4}$. $\mathrm{El}$ antifascismo es el verdadero rasgo genético de un constitucionalismo policy-oriented (como cualquier otro), pero marcado antes por la terrible experiencia de los campos de concentración del nazismo, que por la impronta borrosa de las Declaraciones de Derechos de la "era de las Revoluciones".

Un ethos combativo en defensa de democracia, una "cultura de los derechos fundamentales", según la conocida expresión de Häberle ${ }^{5}$, exigía un nuevo lenguaje constitucional, una "lengua de los derechos" dispuesta para expresar, sobre bases nuevas, el potencial libertador del constitucionalismo, considerablemente menguado a lo largo del decurso histórico del Estado Constitucional.

El proceso de merma de dicho potencial, bajo el estatalismo de signo iuspositivista, culminó en su desactivación más burda, y eso precisamente allí, en la Alemania weimeriana, donde los presupuestos formales de la democracia liberal habían alcanzado su expresión más sofisticada, frente a la alternativa del bolchevismo. Pocos trabajos de teoría constitucional supieron

único", de los trabajos de Pedro de Vega, "Mundialización y Derecho Constitucional: la crisis del principio democrático en el constitucionalismo actual", Revista de Estudios Políticos, 100 (1998), pp. 13 y ss., así como “El tránsito del positivismo jurídico al positivismo jurisprudencial en la doctrina constitucional", Teoría y Realidad Constitucional, 1 (1998), pp. 65 y ss. Sobre la cuestión puede verse también el artículo de Antonio Aguilera Fernández, “Derecho Constitucional y 'Derecha divina'”, Leviatán, 70 (1997), pp. 5 y ss.

4 Cfr. Luis López Guerra, "Las constituciones europeas en el momento actual", "Introducción" a Las Constituciones de los Estados de la Unión Europea, ed. de Germán Gómez Orfanel, Madrid, Centro de Estudios Constitucionales, 1996.

5 Peter Häberle, "Recientes desarrollos sobre derechos fundamentales en Alemania", Derechos y libertades. Revista del Instituto Bartolomé de las Casas, 1 (1993), pp. 149 y ss. 
ver con tanta lucidez lo que estaba acaeciendo, como el que escribiera Gerhard Leibholz en el fatídico año 1933, publicado con el significativo título La disolución de la democracia liberal en Alemania y la forma de Estado autoritaria ${ }^{6}$.

La tesis básica de dicho trabajo es que los valores, primero cristianos, y más tarde secularizados, que habían proveído a la democracia parlamentaria de los fundamentos conceptuales y metafísicos implícitos en ella, se habían visto sometidos a un progresivo proceso de relativización, que había acabado por privar a aquélla de su propio mito y de su propia sustancia. En polémica con las concepciones de Kelsen, y profundizando en un par de trabajos publicados por él mismo poco antes ("Las tendencias actuales de la doctrina del Derecho Público en Alemania", y el ya citado aquí "La formación de los conceptos en el Derecho Público"), Leibholz denuncia los males del relativismo y del positivismo como factores que coadyuvan a la pérdida de un mínimo de referentes valorativos, situando al sistema democrático, a causa de su disposición sustancialmente neutral, "en actitud inerme y suicida frente los movimientos antiliberales y antiparlamentarios" 7 .

Sobre la base de la idea de que la asociación histórica entre democracia y liberalismo no tiene un carácter de necesidad ineluctable, Leibholz acabará propugnando para aquélla una fundamentación específica en valores y creencias, sugerencia que hará plenamente suya la Ley Fundamental de 1949, con sus concepciones de democracia militante y democracia de valores (streitbare demokratie, Wehrhaftedemokratie). Como afirmó el Tribunal Constitucional alemán, en su célebre sentencia de 1956, en la que decretó la inconstitucionalidad del Partido Comunista, "el artículo 21.2 de la Ley Fundamental expresa una consciente voluntad constitucional de resolver un problema límite del orden estatal liberal-democrático, y es resultado de las experiencias

6 Gerhard Leibholz, La dissoluzione della democrazia liberale in Germania e la forma di Stato autoritaria, Milán, Giuffrè, 1996.

7 La dissoluzione della democrazia liberale..., p. 49. 
de un poder constituyente que en una determinada situación histórica creyó no poder permitir ya que se realizara de forma pura el principio de la neutralidad del Estado, reconocimiento de una democracia militante en este sentido"8.

Frente al escepticismo de Settembrini, el personaje de $L a$ Montaña mágica, de Thomas Mann, el constitucionalismo de la segunda posguerra bien podría suscribir las opiniones del coprotagonista de la obra, Naphta, cuando, polemizando con aquél, afirma:

"Querido amigo, el conocimiento puro no existe. La legitimidad del concepto religioso del conocimiento, que puede resumirse con las palabras de San Agustín 'creo a fin de conocer', es absolutamente indudable. La fe es el órgano del conocimiento; el intelecto es secundario. Vuestra ciencia sin premisa es un mito. Hay siempre una fe, una concepción del mundo, una idea; en una palabra, una voluntad, y atañe a la Razón el interpretar y el demostrar, siempre y en todos los casos. Se trata de llegar al quod erat demonstrandum"9.

El quod erat demonstrandum del constitucionalismo de nuestros días es la superioridad ética de la democracia como forma de gobierno, una democracia definida no sólo por la limpieza de las reglas procedimentales para la designación de los representantes, sino también, y sobre todo, por la fundamentación de todo el sistema sobre la premisa antropológico-cultural de la dignidad de la persona. Con el fin de salvaguardar dicha premisa, un constitucionalismo avisado, como el actual, ha acabado por conferir un sesgo radicalmente novedoso a técnicas jurídico-constitucionales que sólo en parte pueden considerarse inéditas: unos valores y unos principios que se preconizan, unos derechos que se garantizan, y un diseño institucional y organizativo congruente con ambos.

8 Sentencia de 17 de agosto de 1956 (BVerfGE 5, 85); cfr. Ignacio de Otto, Defensa de la Constitución y partidos políticos, Madrid, Centro de Estudios Constitucionales, 1985, pp. 22 y ss.

9 Thomas Mann, La Montaña Mágica, Barcelona, Plaza y Janés, 1989, p. 419. 
Valores, derechos e instituciones - las tradicionales partes dogmática y orgánica del texto constitucional - se implican recíprocamente. Las solemnes proclamas dogmáticas, características de lo que hemos llamado el momento del auge constitucional, han sido sustituidas en el constitucionalismo de nuestros días por un lenguaje más sobrio, un lenguaje adecuado para expresar en términos normativos las grandes decisiones de principio, dotando de efectividad a un determinado orden axiológico o sistema de valores.

Tal estimativa constitucional viene emplazada allí donde se trata de establecer los fundamentos del sistema, con el preciso objetivo de situarla en disposición de ejercer un influjo irradiante sobre la totalidad del ordenamiento. Con respecto a éste, la estimativa constitucional actúa, pues, como un gran parámetro que combina elementos de indeterminación y elementos de concreción; y es también una guía sugerente a cuya luz puede observarse el contenido de cualquier norma, con independencia de su rango, fundamentando un juicio de concordancia o de discordancia entre aquella estimativa y la norma en cuestión.

El Derecho de la Constitución se plantea así como tarea el progreso de la tendencia a los valores o, dicho en otros términos, se erige en defensor del orden social de los valores ${ }^{10}$. Éstos, como afirma Tomás y Valiente, y los principios constitucionalizados, no son "música celestial", sino normas positivas vinculantes para el intérprete, y portadoras de lo que Peces Barba - otro pionero en el tratamiento de la cuestión entre nosotros - llama la "moralidad crítica"11.

Pero lo que nos interesa destacar es que esta (relativamente) novedosa faceta del constitucionalismo, su fundamentación en valores y en principios que participan en plenitud de la fuerza

\footnotetext{
10 Cfr., in extenso, el trabajo pionero de Pablo Lucas Verdú, Estimativa y Política constitucionales, Madrid, Facultad de Derecho de la Universidad Complutense, 1984, passim.

11 Gregorio Peces Barba, Los valores superiores, Madrid, Tecnos, 1984, pp. 34 y ss. La referencia a Tomás y Valiente lo es a su trabajo "La resistencia constitucional y los valores", Doxa, 15-16 (1994), pp. 635 y ss.
} 
normativa de la Constitución, parece haber trastocado no ya las construcciones tradicionales de quienes en el pasado hicieron del Derecho Público su campo de estudio, sino las de la ciencia del derecho tout court. La positivización de los principios y los derechos, junto a la consolidación del control de constitucionalidad de las leyes, como expedientes nuevos al servicio de ideales viejos, aunque actualizados y quizás cada vez más exigentes, han dado un giro considerable a los topo $i$ propios del Derecho Constitucional.

El problema de la interpretación de la Constitución, los que se derivan de la posición de la justicia constitucional y el valor de sus decisiones y, por encima de todo, el que plantea una Constitución de las características actuales como fundamento del sistema, son cuestiones que se sitúan ahora en el centro de la reflexión.

\section{Moral institucional y paradigma constitucional}

Comenzando por la última de las cuestiones anotadas, la de alcance más genérico, parece fuera de toda duda que el constitucionalismo de nuestros días replantea el viejo problema de las relaciones entre Constitución y sociedad sobre bases más sofisticadas de lo que lo hacía el constitucionalismo mesiánico de la era de las revoluciones. Mesiánico en el sentido de que fiaba su capacidad de influencia sobre las relaciones sociales en el mero hecho (taumatúrgico) de la existencia del documento. Por eso era un constitucionalismo de proclamas, de proclamas en su mayor parte no cumplidas. Por su parte, el constitucionalismo moderado que impera en la Europa del XIX, es un constitucionalismo desentendido de la sociedad, un constitucionalismo que arroja como resultado la glorificación del Estado, y el blindaje frente a la sociedad del ámbito de lo jurídico.

En contraste, la relación entre Constitución y sociedad se plantea hoy (por decirlo con el término que tanto gusta utilizar a los anglosajones) como feedback, es decir, como una relación de retroalimentación o influencia recíproca, de manera que los 
enunciados sustanciales del texto constitucional se van llenando de significado mediante la implementación de los mismos por los agentes sociales y/u operadores jurídicos. Esto podría considerarse como algo ya contemplado en la teoría smendiana de la integración, o bien en la (por nosotros denostada) tesis de la Constitución material. Pero, como ocurre siempre que construimos teorías, son los matices lo que importan.

No se trata de que la Constitución sea lo que los jueces, o los legisladores, o los ciudadanos, o quien quiera que sea, digan que es. El orden constitucional tampoco es un mero referente institucional dispuesto para incentivar los procesos de identificación de una sociedad consigo misma, ni se trata del resultado indeterminado, pero determinable, a través de la interrelación de las fuerzas políticas actuantes en un cierto tiempo.

La Constitución genuinamente democrática es, en nuestros días, una Constitución dirigente; dirigente no por la predeterminación rígida de objetivos políticos (lo que puede $\mathrm{y}$, como muestra la experiencia de Constituciones bien próximas a la nuestra, suele, abocar a un conflicto entre voluntad constituyente y voluntad de las mudables mayorías constituidas a lo largo del tiempo), sino dirigente en el sentido de dotada de efectividad normativa. Esta efectividad se alcanza a través del despliegue del proceso político de manera conforme a los cauces previstos en la Constitución (Constitución "de procedimientos"). Y se conquista mediante el proceso de adaptación jurídica (y la consecuente realización social) de las disposiciones sustanciales - valores, principios, derechos - de la Constitución.

La Constitución recoge enunciados normativos, cuyo grado de concreción varía en proporción inversa al margen de que dispone el legislador para objetivar tales enunciados. Y una vez objetivados, su proceso aplicativo se traduce en una subjetivización dialéctica de los mismos (confrontación aplicativa y, en su caso, jurisdiccional en sus distintos niveles, intra y supra nacional), que contribuye decisivamente a precisar/concretar el contenido del enunciado constitucional. 
Una regulación constitucional "lograda" será aquella, en suma, cuya elasticidad no vaya en menoscabo de su intensidad prescriptiva; o, dicho de otro modo, una Constitución que no llegue a ser percibida ni como una rémora, desde el punto de vista de la fluidez del cambio social, ni como la mera formalización, confusa y estéril, de una inaprensible realidad política.

En tales condiciones, la Constitución se presenta no tanto como el producto de una férrea voluntad constituyente, entendida como polo fijo o baluarte de certeza, sino (por decirlo en los ya evocados términos de Niklas Luhman) como una "conquista evolutiva"12. Para la descripción del decurso constitucional, resulta más operativa la imagen de la Constitución como un centro de convergencia o polo de gravitación del pluralismo político-social, que la imagen de la misma como el punto de partida de un sendero jurídico-político trazado de antemano.

Tras la época de las grandes construcciones doctrinales, en la que la búsqueda de un concepto satisfactorio de Constitución se resolvía en la yuxtaposición de conceptos parciales, los constitucionalistas acusamos hoy mayores dosis de escepticismo teórico. El Derecho Constitucional ha dejado de atormentarse con las recurrentes dualidades que le han acompañado siempre (lo formal-jurídico frente a lo real-social, el poder constituyente estático frente al poder constituido dinámico), de manera que parece haberse convertido, dicho sea sin matiz peyorativo alguno, en una ciencia mucho más práctica. Parafraseando a Konrad Hesse, podría decirse que no nos importa tanto el concepto como la cualidad de la Constitución.

Claro que el que la Constitución pueda desplegar sus cualidades es algo que está condicionado por el concepto que se sustente de la misma en el momento de establecer el texto,

\footnotetext{
12 Niklas Luhman, "La costituzione come conquista evolutiva", cit, pp. 83 y ss; más recientemente, pueden verse las reflexiones en torno a la misma idea de Antonino Spadaro, “Dalla Costituzione come atto (puntuale nel tempo) alla Costituzione come processo (storico). Ovvero della continua evoluzione del parametro costituzionale attraverso i giudizi di costituzionalità", Quaderni Costituzionali, 3 (1998), pp. 343 y ss.
} 
así como de la adecuación de éste a las necesidades políticas y sociales, y su consiguiente capacidad para suscitar un pacto de acatamiento perdurable en el tiempo. En la misma medida en que la Constitución constituye a la sociedad, y se estabiliza como forma política de la unidad social ${ }^{13}$, su efectividad demanda un compromiso de reconocimiento. $Y$ de dicho compromiso, sustentado sobre un ethos constitucional ampliamente compartido y renovado de continuo, depende, en último extremo, la supervivencia de una Constitución que se asienta en la soberanía popular, axiológicamente fundada, y que se pretende normativa.

En 1934, Karl Llewellyn, una de las figuras señeras del llamado realismo jurídico norteamericano, reclamaba una nueva teoría constitucional que diera cuenta del carácter de la Constitución no como un documento, sino como una institución:

"una Constitución es, en cierto modo, una peculiar institución en cuyo seno se desenvuelve el modo habitual de comportamiento de un gran número de personas, por no decir la casi totalidad de la población. Si, como ocurre con la nuestra, se trata de una Constitución firmemente asentada, (...) no sólo lleva dentro de sí modelos habituales de conducta (o de inhibición) de las personas, sino que incluye también pautas emocionales y de pensamiento, es decir, actitudes perfectamente predecibles con respecto al símbolo verbal 'Constitución', y con respecto a cualquiera que se atreva a oponerse a ella"14.

Una reconstrucción teórica de tal naturaleza - prosigue Llewellyn en su inglés farragoso - capaz de presentar la Constitución no como el Documento, sino como la institución dotada de vida, aunque histórica y genéticamente condicionada por éste, "permitiría explicar de forma clara los hechos y las razones

\footnotetext{
13 En este aspecto de la Constitución como norma constitutiva de un proyecto de vida en común insiste Garrorena Morales en la Primera tesis de su ensayo "Cuatro tesis y un corolario sobre el Derecho Constitucional", Revista Española de Derecho Constitucional, 51 (1997), pp. 37 y ss.

14 Karl Llewellyn, "The Constitution as an Institution", Columbia Law Review, XXXIV (1934), pp. 2 y ss.
} 
que llevaron al Tribunal Supremo a adoptar sus decisiones más erráticas" (would make clear both the fact of and the reasons for the major vagaries of the Court's action).

Es probable (pues el autor en absoluto lo dice) que, al escribir las líneas que anteceden, Llewellyn pudiera tener in mente la que pasa por ser la más desacertada decisión del Tribunal Supremo norteamericano de todos los tiempos: la del caso Dred Scott, en la que, entre otras cosas, el juez Taney sostuvo que el Congreso no estaba legitimado para dar paso alguno encaminado a la abolición de la esclavitud ${ }^{15}$.

Dred Scott es el fantasma que airean los antipositivistas y antirrealistas de toda laya y condición para denunciar la inconsistencia del célebre aforismo, atribuído al chief justice Hughes "vivimos bajo una Constitución, pero la Constitución es lo que los jueces dicen que es"16. Un postulado que, al menos en materia constitucional, no admite, por la lógica de las cosas, la posibilidad de decisiones judiciales equivocadas.

En contra de un escepticismo tan descarnado se alzan aquellas teorías que defienden la incorporación a la Constitución de una moral bajo cuyo rasero resulta posible valorar lo acertado o desacertado de la hermenéutica constitucional; así ocurre con la teoría de la moral institucional formulada por Dworkin, y desarrollada, con matices diferenciales, por MacCormick.

Dworkin insiste en el valor fundamental de unos derechos implícitos (background rights), que devienen operativos a través de su plasmación en una moral institucional:

"Nuestro sistema constitucional - resume Dworkin - se funda en una concreta teoría moral, señaladamente, en la idea de que los individuos son titulares de derechos morales frente al Estado. Las cláusulas difíciles de la declaración de derechos, como por ejemplo la del proceso debido, o

\footnotetext{
15 Dred Scott v. Sanford, 60 U.S. (19 Howard), 393 (1857)

16 La frase, según Robert Bork, fue pronunciada en un discurso que Hughes dio en Elmira (Nueva York), el 3 de mayo de 1907; cfr. The Tempting of America. The Political seduction of the Law, Nueva York, Simon and Schuster, 1990, Cpt. VIII ("Objections to Original Understanding").
} 
la de la igual protección frente a la ley, han de ser así entendidas como una apelación a conceptos morales, antes que como la expresión de concepciones concretas; de ahí que cualquier tribunal que asuma la carga de aplicar tales cláusulas, extrayendo plenamente de ellas las consecuencias jurídicas, tiene que ser por fuerza un tribunal activista, en el sentido de que ha de estar preparado para plantearse, y resolver, problemas de moralidad política" ${ }^{17}$.

La filosofía jurídica de Dworkin es, como se ha dicho, una filosofía incómoda, debido a que pone en cuestión el presupuesto, bien arraigado en nuestra mentalidad de juristas, de la separación del derecho y la moral ${ }^{18}$. Algo que, a poco positivista que se sea, - y todos cuantos nos hemos formado "a golpe de Código”, aún faltándonos Constitución, lo somos en mayor o menor medida - no deja de suscitarnos reparos. De ahí que, en la producción doctrinal de nuestros días, haya pocas obras más discutidas (e influyentes) que Los derechos en serio, como consecuencia de la radicalidad de sus postulados centrales: la presentación del Estado y el orden jurídico como meros instrumentos al servicio de la garantía de derechos, y la defensa del derecho a triunfar de los derechos individuales frente al bienestar colectivo o las decisiones de la mayoría.

De la obra de Dworkin se ha dicho que representa un mero aggiornamento del iusnaturalismo constitucional propio de la tradición norteamericana ${ }^{19} \mathrm{y}$, por lo mismo, inadecuada para ser transpuesta mecánicamente a nuestro Derecho de (rancia) impronta continental ${ }^{20}$. Pero, sea como fuere, el autor angloamericano ha sabido, como nadie, atraer la atención sobre las peculiaridades de un estilo argumentativo en el que la norma

\footnotetext{
17 Ronald Dworkin, Taking Rights Seriously, Cambridge, Harvard University Press, 1978, p. 147.

18 Cfr. Albert Calsamiglia, ¿ ¿Por qué es importante Dworkin?, Doxa. Cuadernos de Filosofía del Derecho, 2 (1985), pp. 159 y ss.

19 Cfr, Giorgio Rebuffa, "Costituzionalismo e Giusnaturalismo: Ronald Dworkin e la riformulazione del Diritto Naturale", Materiali per una Storia della Cultura Giuridica, X (1980), pp. 212 y ss.

20 No hay que olvidar que el propio Dworkin presenta la evolución del sistema constitucional norteamericano como una paulatina plasmación de los ideales inscritos en la Constitución.
} 
positiva, lejos de excluir, reclama el planteamiento de dilemas sobre principios fundamentales. Así sucede con mucha frecuencia en el ámbito del Derecho Constitucional, a uno y a otro lado del Atlántico, por más que ello pueda ser motivo de descontento para los entusiastas de la certeza del derecho.

Cercanas a las premisas de Dworkin, aunque desde presupuestos rigurosamente positivistas, se hallan las ideas expuestas por Neil MacCormick, en diálogo con aquél:

"Allí donde hay Derecho Constitucional - dice MacCormick - tiene que existir también teoría constitucional; y la teoría constitucional ha de basarse necesariamente en una visión del Estado constitucional como Estado que aspira a ser un ordenamiento moral" ${ }^{21}$.

MacCormick se proclama heredero de una tradición doctrinal que explica la Constitución británica al estilo Dworkin; así, por ejemplo, Dicey y su exposición del sistema constitucional sobre la base de dos principios: la soberanía del Parlamento y la rule of law, de cuyo contenido son parte fundamental unos derechos que, conforme son interpretados y defendidos por los Tribunales, son la fuente, y no la consecuencia, de la Constitución. Así también John Austin, para quien el Derecho Constitucional es, en gran medida, "moral positiva", asentada en costumbres y usos de cuya repetición mecánica depende la propia supervivencia de la Constitución ${ }^{22}$.

Tal es el punto de vista abrazado por MacCormick, al defender el valor de la costumbre como "un producto de la razón práctica de los seres humanos aplicada a la necesidad de asegurar un marco estable para la convivencia”. El consenso básico sobre las reglas del juego constitucionales tendría así por objeto un valor bien simple y general: el valor de la convivencia

21 N. MacCormick, "La morale istituzionale e la costituzione", en N. MacCormick y 0. Weinberger, II diritto come istituzione (a cura di Massimo La Torre), Bolonia, Seminario Giuridico della Università di Bologna, 1992, pp. 213.

22 John Austin, The Province of Jurisprudence determined, Cpt. VI, y su opúsculo de 1859, menos conocido, Plea for the Constitution; cfr. MacCormick, "La morale istituzionale...", cit. 
ordenada frente al caos, y la "moral institucional", descrita por Dworkin, resultaría, en definitiva, según el autor que ahora glosamos, un meritorio intento de exponer esa racionalidad práctica como un conjunto articulado de principios.

Se compartan o no las ideas de Dworkin sobre el peso de los derechos, sobre el juez hercúleo, o sobre la "única respuesta correcta" $^{23}$, hoy está fuera de duda que la teoría jurídica tradicional hace aguas por todas partes a la hora de explicar el significado de la vinculación de los poderes públicos (y de los ciudadanos) a la Constitución. Empleo ahora los términos "teoría tradicional" de manera imprecisa y seguramente inaceptable para cualquiera que se halle mínimamente familiarizado con los entresijos de la filosofía jurídica ${ }^{24}$.

La llamo "tradicional", porque ella fue la que marcó la pauta de los momentos iniciales de la formación como juristas de las personas de mi generación. Lo que estudiábamos entonces era un derecho sin Constitución, un derecho plagado de brocardos con algunos siglos de existencia, en el que se pasaba como sobre ascuas por el momento de la creación de las normas, y en el que éstas, sobre todo si estaban encerradas en un Código, se nos aparecían como el armazón de un sistema no ya coherente, sistemático y completo - como repetían los entusiastas de la exégesis - sino además razonable y seguro. Razonable no porque fuera compatible con la única razón que hoy nos parece que puede sustentar la convivencia, la razón democrática, sino por su cartesianismo, en tanto que sistema. Y seguro no porque

23 Sobre esto último, se lee con gusto el diálogo epistolar mantenido por Alejandro Nieto y Tomás Ramón Fernández, aquél tan iconoclasta y heterodoxo como de costumbre, publicado bajo el título El Derecho y el revés, Barcelona, Ariel, 1998. Las tesis de Alejandro Nieto sobre la falacia de la "única respuesta correcta", han sido desarrolladas in extenso en su libro El arbitrio judicial, Barcelona, Ariel, 2000.

24 En la doctrina norteamericana dicha doctrina "tradicional" se correspondería con el allí Ilamado Classical legal thought, el paradigma teórico que hizo crisis durante los años 30 del pasado siglo, de forma paralela a la implantación del New deal. Tal crisis está muy bien descrita en la monografía de José Ignacio Solar Cayón, Política y Derecho en la era del New Deal. Del formalismo al pragmatismo jurídico, Madrid, Instituto Bartolomé de las Casas-Dykinson, 2002. 
pusiera a los ciudadanos a resguardo de las arbitrariedades del poder, sino porque venía considerado como fuente de toda certeza por el mero hecho de su publicación en el $B O E$. Un derecho, en suma, que orillaba la cuestión de la legitimidad, que ensalzaba el derecho legislado, y que (probablemente de buena fe) continuaba creyendo en el valor del silogismo como sustento lógico de la correcta aplicación del derecho.

Naturalmente, se trata de una visión del pasado groseramente esquemática y un tanto esperpéntica, lo que no hace justicia a aquellos profesores que acostumbraban a elevar el vuelo por encima de las certezas del ius positum y su dogmática, un vuelo, por cierto, no siempre realizado en nombre de la razón democrática.

Sea como fuere, en un ambiente jurídico de tales características, sobre todo y antes que cualquier cosa, legicentrista y celoso guardián de unas tradiciones romano-canónicas-continentales, no es exagerado aplicar a la entrada en vigor de una Constitución autoproclamada vinculante, y con vocación fundamentadora, el dicho "como elefante por cacharrería".

Nunca dejará uno de admirar qué singulares circunstancias de concordia política y finura intelectual hubieron de concurrir como para que, en el espacio de pocos meses, nuestra secular e indiscutida cultura de código comenzara a experimentar el impacto de una ambiciosa cultura constitucional que necesariamente había de remover, para imponerse, muchos de los viejos cimientos. Aquí no se hizo honor a Lampedusa. Hubo un giro copernicano que transformó efectivamente nuestra práctica y nuestra cultura del Derecho. Ello demuestra, dicho sea de paso, que quizá no era tan rancio el clima docente de la Universidad en la que nos formamos desde mediados de los años 70, ni tan acusado el déficit crítico que creíamos percibir. De otro modo, no hubiera sido posible el fecundo debate doctrinal inmediato a la entrada en vigor de la Constitución ${ }^{25}$, ni se habría hecho

25 Estoy pensando en mis primeras lecturas sistemáticas sobre el conjunto del texto constitucional: Ios dos volúmenes publicados por la UNED, en 1978, bajo el título Lecturas 
realidad, con tanta prontitud, la existencia de un Tribunal Constitucional $^{26}$.

Si atendemos a esa revolución en los supuestos de partida, y nos fijamos en una práctica jurídica que cada vez tiene menos que ver con las tranquilizantes certezas de un derecho escrito, dotado de precisión en sus enunciados normativos, y emanado de un único centro de imputación, resulta tanto más sorprendente comprobar las resistencias que todavía suscitan las teorías que pretenden dar cuenta de la nueva realidad. Así ha sucedido, de manera paradigmática, con un libro cuya lectura incita a un cuestionamiento radical de los hábitos mentales con los que solemos aproximarnos al fenómeno jurídico. Me refiero al Diritto mite, de Gustavo Zagrebelsky, traducido aquí (en feliz aportación de la responsable de la versión española) como El derecho dúctili ${ }^{27}$.

sobre la Constitución española, el dirigido por Manuel Ramírez, Estudios sobre la Constitución española de 1978, Zaragoza, Pórtico, 1979 y, sobre todo, el libro dirigido por Predieri y García de Enterría, La Constitución española de 1978, Madrid, Cívitas, 1980.

26 La primera resolución de fondo del Tribunal Constitucional es un Auto, el 1/1980, datado el 11 de agosto. El actor desistió de su pretensión (el cobro de una pensión de jubilación como miembro del extinto Cuerpo republicano de Seguridad y Asalto) al haber obtenido satisfacción extraprocesal de la misma. De todos modos, denota la confianza desmedida depositada por el actor en el Tribunal el hecho de que su demanda incurriera en causa de inadmisión por carecer de dirección letrada y representación procesal. Hasta el mismo momento de escribir estas líneas, no habíamos reparado en que la recopilación de la jurisprudencia constitucional copatrocinada por el propio Tribunal Constitucional y por el $B O E$, contiene una jugosa "Presentación" de García Pelayo, en la que el entonces presidente de la institución realiza una apasionada defensa de la jurisdicción constitucional. Función de ésta, escribió, "no es sólo interpretar la Constitución como si se tratara de una simple ley, sino desarrollarla, proseguirla y precisarla, asegurando así su estabilidad ante distintas circunstancias y coyunturas históricas. Con ello - concluye García Pelayo - contribuye a fortalecer la seguridad jurídica en materia constitucional, lo que, dada la naturaleza fundamentadora de la Constitución, conlleva el fortalecimiento del ordenamiento jurídico todo".

27 G. Zagrebelsky, El derecho dúctil. Ley, derechos, justicia, traducción de Marina Gascón, con epílogo de Peces-Barba, Madrid, Trotta, 1995; cfr. la amplia atención que dispensó a la obra el Anuario de Filosofía del Derecho, XIII (1996), con artículos de Marina Gascón, Enoch Albertí, Perfecto Andrés, Roberto Blanco, José Antonio García Amado, Alfonso García Figueroa, Ricardo Guastini y Luis Prieto Sanchís. 
Hace años que éramos conscientes de que la ley - por decirlo coloquialmente - había dejado de ser lo que era. El ingreso en la "edad de la descodificación" había conllevado el final de los tiempos de la concordia entre la legalidad y la legitimidad, con la ley como zona de encuentro ${ }^{28}$. Zagrebelsky no necesita arrancar de ahí para explicar en qué han cambiado los cuatro o cinco axiomas en torno a los cuales funciona el Estado constitucional desde hace dos siglos. Más bien se quita la venda histórica, y lo que aparece ante sus ojos, una vez desprovistos de los resabios de aquella naturaleza, es un derecho bastante desordenado; un derecho que acusa el derrumbe del mito de la soberanía estatal y una ley de cuyas entrañas se han seccionado los derechos y aún la propia idea de justicia. El derecho desordenado, incluso caótico en muchas de sus manifestaciones, resulta funcional a las necesidades de una sociedad compleja como la de nuestras (llamadas) democracias avanzadas, porque su mitezza, esto es, su elasticidad, su maleabilidad esencial, es precisamente la que permite el acuerdo de la gran mayoría sobre algunos principios básicos que subsisten y se refuerzan con el paso del tiempo. En tanto que sede donde tales principios aparecen objetivados, la Constitución deviene así un centro hacia el que todo converge, un "compromiso de la posibilidad", del que sólo cabe predicar con carácter absoluto y, en tal sentido, soberano, "la doble exigencia de mantener el pluralismo de los valores (por lo que se refiere a su aspecto sustancial), así como el de asegurar la leal confrontación entre ellos (en lo que respecta a la vertiente procedimental)"29.

No incurriré aquí en el error de proseguir con el intento de resumir uno de los libros jurídicos más leídos de los últimos años. Lo que me interesaba destacar es lo difícil que todavía nos resulta asumir que el trono no es susceptible de reparto. Si

28 Es inevitable la referencia a la obra, ya clásica, de Natalino Irti, L'età della decodificazione, Milán, Giuffrè, 1979.

29 Cito por la versión original italiana, // diritto mite. Legge, diritti, Giustizia, Turín, Einaudi, 1992, p. 11. 
entronizamos la Constitución, entonces la ley queda desplazada, como todo el mundo admite. Y con una ley sometida al imperio de la Constitución es inevitable que se resientan las posiciones de todos: la del autor de la ley, el legislador, por muy democrático que sea, pero también la del juez independiente, aunque sujeto a ella, y la de la Administración, con su enigmática doble vinculación a la ley y al Derecho y, en fin, la de los operadores jurídicos todos, a cuyo cuidado queda el funcionamiento de un sistema que no admite ya hegemónicos "señores del Derecho".

El autor italiano se refiere al Derecho Constitucional como un "conjunto de materiales de construcción" cuya combinación concreta, a los efectos de levantar el edificio, viene determinada por la política constitucional. Materiales de construcción, que no de derribo, pero que en cualquier caso parecen exigir un replanteamiento de categorías con las que seguimos empeñados en habérnoslas, aunque sea al precio de desconocer la realidad. En esa tarea, nadie está llamado a tener tanta responsabilidad como nosotros, los profesores, en nuestra condición de autores de doctrina; y especialmente los constitucionalistas, dadas las insuficiencias de que adolece la teoría constitucional que venía considerada hasta hace bien poco como dominante ${ }^{30}$.

A la vista del funcionamiento de un constitucionalismo como el de nuestros días, la teoría del derecho viene realizando algunas aportaciones que resultan de gran interés para nuestro gremio. Entre las dos venerables aproximaciones tradicionales a la fundamentación de lo jurídico, el iusnaturalismo y el iuspositivismo, el constitucionalismo está emergiendo, en efecto, cada vez con mayor fuerza, como un complejo tertium genus. Y eso hasta el punto de que una influyente corriente doctrinal se muestra convencida de que la cultura jurídica de nuestros días está imbuida de un nuevo paradigma: precisamente, el paradigma constitucional y "garantista"

30 Teoría trasladada en algunos casos, de manera irreflexiva, al propio texto de la Constitución, como ocurre con la regulación del control parlamentario, realizada manifiestamente con total ignorancia de la práctica del Estado de partidos. 
Unas cuantas páginas más arriba nos referimos ya a las dificultades que plantea el intento de encajar el constitucionalismo, como doctrina referida a los límites del poder, con el positivismo en cualquiera de sus vertientes o, al menos, en cualquiera de sus vertientes clásicas ${ }^{31}$. Es más, una de las tesis centrales de estas páginas es que el positivismo decimonónico falseó el constitucionalismo, neutralizando el potencial libertador inscrito en el gran tríptico de ideales de la Revolución francesa. Por otra parte, también hemos sostenido que la reconstrucción del constitucionalismo, tras las cenizas de la guerra, se realizó mediante la incrustación en el Derecho Constitucional, ergo en el Derecho positivo, de un determinado orden de valores, en respuesta al horror y la indignidad del más inmediato pasado.

Un constitucionalismo de tal naturaleza no necesita saldar cuentas ni con el iusnaturalismo, ni con el iuspositivismo. En realidad el constitucionalismo raras veces necesitó saldar cuentas con el primero. Su relación fue de perfecta armonía en los momentos del apogeo revolucionario burgués - la Constitución como instrumento para el traslado del Derecho Natural al mundo efectivo -, quedó eclipsada durante el largo auge del iuspositivismo legalista, y reapareció, en términos de conflicto, precisamente cuando los supuestos políticos de fondo no consentían ya la manipulación de la ley al servicio de los intereses de una sola clase social. Es entonces, en los convulsos años de la Alemania de Weimar, cuando la incipiente razón democrática, a la sazón concentrada exclusivamente en el legislador, recibe el embate de un Derecho Natural, reformulado entonces, bajo la larga estela del romanticismo jurídico, con concepciones tales como el "sagrado derecho del pueblo", la "naturaleza de las cosas", la "realidad de la vida", etc. ${ }^{32}$.

\footnotetext{
31 Epígrafe "Positivismo versus constitucionalismo".

32 El conflicto se centró, como es sabido, en torno a la disponibilidad de la ley por los jueces - una casta por entonces especialmente reaccionaria - sobre todo, a propósito de la aplicación del principio de igualdad consagrado en el artículo 109.1 del texto constitucional de Weimar. La cuestión fue el objeto central de debate de la reunión de profesores alemanes
} 
Quienes redactaron los textos constitucionales de la posguerra conocían bien dicho conflicto, pero no por ello renunciaron a insuflar el derecho de la Constitución con los aires de un cierto iusnaturalismo, convenientemente puesto al día. Al fin y al cabo, se trataba de un problema de cálculo de riesgos y de disposición de medios para proteger la Constitución frente a posibles degeneraciones u operaciones de boicot.

Dicho de manera sintética: si la vexata quaestio del constitucionalismo no ha sido otra, históricamente, que la del control del poder por el derecho, con una neta contraposición entre razón política y razón jurídica, la cuestión se nos presenta más bien en nuestros días como la de los controles recíprocos entre unos poderes, que son más, y de distinta naturaleza, que los tres tradicionales, y donde la razón constitucional, en cuyo nombre se disponen los controles, hace mucho más difusos los confines que delimitan la política y el derecho ${ }^{33}$.

Si las cosas parecen ser así, hablando en términos generales, ¿qué no decir de los riesgos del iusnaturalismo en un país como el nuestro, hasta hace bien pocos años un erial en materia de canalización jurídica de la política, y (quizá por ello) tan aficionado a glorificar unos principios generales del

de Derecho del Estado, celebrada en Munich, en 1926. Un año antes, el Tribunal del Reich para asuntos civiles había reivindicado con éxito "el derecho que corresponde a los jueces desde tiempo inmemorial" de verificar un control de la ley, desde el punto de vista de su concordancia material con la Constitución. En su Estado de derecho o Dictadura, Herman Heller comenta en términos amargos esta decisión, mediante la cual, en su opinión, “la burguesía (habría) logrado por el momento asegurarse eficazmente contra el riesgo de que el poder legislativo popular transforme en social el Estado de Derecho liberal" (Herman Heller, cit. nota 68, p. 288). En términos más generales, sobre el mencionado conflicto y su contexto, puede verse el libro de Giuseppe Volpe, L'ingiustizia delle leggi, Milán Giuffrè, 1977, especialmente Cpt. II ("II Romanticismo Giuridico"), con amplia glosa de decisiones judiciales concretas.

33 Con respecto a la enumeración de los poderes, es interesante la tipología propuesta por Jorge de Esteban, quien distingue en nuestra Constitución de 1978 "siete más uno”, a saber: el electoral, el moderador, el corrector, el ejecutivo, el parlamentario, el judicial, el constituyente-constituido y el autonómico. Un criterio de división semejante constituye el hilo conductor de los tres volúmenes de su Curso de Derecho Constitucional, publicado conjuntamente con Pedro J. González Trevijano. 
derecho, nunca bien definidos ni perfilados, pero sí presentados como la materialización de la Justicia -naturalmente con mayúscula- frente a las contingencias y los defectos de la ley positiva? Una tradición semejante justifica toda la pasión que pueda emplearse en defensa de la ley, como expresión de la voluntad democrática, a la par que explica por sí sola la cautela (a la que antes nos referíamos) con la que alguna de las tesis de El Derecho dúctil ha sido acogida entre nosotros ${ }^{34}$.

Pero volvamos al asunto. El constitucionalismo valorativo - de valores llamados superiores, y de principios de muy diversas naturaleza y alcance - tampoco necesita realizar liquidación de cuentas alguna con el positivismo. ¿Cómo iba a precisar hacerlo si de lo que se trata exactamente es de hacer partícipe a la Constitución de las características propias de todo derecho positivo? Lo radicalmente nuevo no es que el texto de las Constituciones haya acabado por incorporar prescripciones propias del Derecho Natural, sino la difusión de una idea que, hace bien poco tiempo, no habría sido admitida, al menos en términos generales: la de que no puede haber democracia sin Constitución normativa. Normativa significa dotada de medios para asegurar la sujeción a ella de poderes e individuos o, lo que es igual, con vocación de efectividad, por cuanto prevé la manera de reaccionar contra, e impedir la perpetuación de, lo opuesto a ella.

El constitucionalismo abomina tanto del subjetivismo iusnaturalista, como de la ciega objetividad del Estado legislativo de derecho. Su condición de tercero en discordia proviene, en definitiva, de lo que repudia, pero también de lo que toma de

\footnotetext{
34 Cfr. la recensión de Francisco Rubio Llorente, de todos modos muy encomiástica, en Revista Española de Derecho Constitucional, 40 (1994), pp. 427 y ss., así como el "Epílogo", éste más crítico, de Gregorio Peces-Barba a la edición española de la obra, publicada por Trotta en 1994. Sobre el papel atribuido tradicionalmente en España a los principios generales del derecho, y la necesidad de "ponerlos en su sitio", tras la entrada en vigor de la Constitución, son muy interesantes las consideraciones que realiza el propio Rubio Llorente en su prólogo a la obra colectiva, dirigida por él, Derechos fundamentales y principios constitucionales (doctrina jurisprudencial), Barcelona, Ariel, 1995.
} 
una y de otra forma de pensamiento jurídico. Si el positivismo absolutiza la ley, el constitucionalismo hace de ella algo problemático, aunque sólo en aras de la supremacía de la Constitución, con su entramado de normas positivas, admite que pueda ser puesta en entredicho. Si el iusnaturalismo condiciona el ser de la norma a su correspondencia con el deber ser estatuido en un derecho natural cuyas prescripciones son abiertas e indeterminadas, el constitucionalismo delimita cuidadosamente el parámetro crítico, y además lo sitúa en el más alto nivel del derecho positivo.

Es, sobre todo, esa novedosa escisión del orden jurídico positivo en dos niveles, ese "Derecho sobre el derecho", que confiere a la Constitución (según nuestro Tribunal Constitucional) el carácter de "norma cualitativamente distinta de las demás, por cuanto incorpora el sistema de valores esenciales que ha de constituir el orden de convivencia política y de informar todo el ordenamiento jurídico" (STC 9/1981, FJ 3), la que permite hablar de un nuevo paradigma en la ciencia del Derecho.

Dicho paradigma, situado a medio camino entre el iuspositivismo y el iusnaturalismo, no es otro que el constitucionalismo. Al menos así lo sostiene hoy, con notable pujanza, un amplio sector de cultivadores de la teoría del Derecho: por dar algunos nombres, entre los muchos que podrían citarse, Alexy, Ferrajoli y Guastini y, en España, Prieto Sanchís y García Figueroa ${ }^{35}$. Según Ferrajoli, a resultas de la positivización del Derecho Natural se ha producido una aproximación entre legitimación interna, o deber ser jurídico, y legitimación externa, o deber ser extrajurídico, es decir, "una juridificación de este último mediante la interiorización en el derecho positivo de muchos de los viejos

35 De inexcusable cita al respecto es el libro colectivo Neoconstitucionalismo(s), Madrid, Trotta, 2003, coordinado por Miguel Carbonell y con contribuciones de Ferrajoli, Alexy, Guastini, Comanducci, Moreso, Prieto Sanchís, García Figueroa, Pozzolo, Bayón, Sastre Ariza y Barberis. Dentro de él resulta de especial interés el trabajo de Comanducci, "Formas de (neo)constitucionalismo: un análisis metateórico". Y por su carácter pionero en la doctrina española también es de rigor remitir al libro de Luis Prieto Sanchís, Constitucionalismo y positivismo, México, Fontanara, 1999. 
criterios y valores sustanciales de legitimación externa que habían sido expresados por las doctrinas ilustradas del derecho natural". Y en tales condiciones,

"el antiguo conflicto entre derecho positivo y derecho natural y entre positivismo jurídico y iusnaturalismo ha perdido gran parte de su significado filosófico-político, al haberse cambiado los términos de la separación entre derecho y moral, entre validez y justicia, entre derecho como es y derecho como debe ser. La diferencia entre ser y deber ser del derecho expresado por la vieja dicotomía ley positiva/ley natural se ha transformado en gran medida en una diferencia entre ser y deber ser en el derecho, trasladándose al tejido mismo de los ordenamientos jurídico positivos y configurándose como incoherencia o antinomia entre sus diferentes niveles normativos: entre la constitución y la ley, entre la ley y la jurisdicción, entre la ley y las actividades administrativas, ejecutivas y de policía"36.

Para Ferrajoli, la marca distintiva del Estado constitucional de nuestros días reside precisamente en el hecho de que las condiciones de validez de las normas no sólo atañen a su regularidad formal, sino también a su contenido sustancial -esto es lo que otro filósofo del derecho italiano denomina rematerialización de la Constitución ${ }^{37}$-, de donde extrae un decisivo distingo entre vigencia de la norma, referida al aspecto formal de la regularidad del acto normativo, y validez de la misma, centrada en la adecuación constitucional de su contenido ${ }^{38}$.

El paradigma constitucional produce además una relación de tipo circular entre la normatividad del Derecho y una teoría jurídica que también aspira a ser normativa. Centro de atención de dicha teoría no es sólo, en efecto, el derecho vigente,

36 Luigi Ferrajoli, Derecho y Razón. Teoría del garantismo penal, Madrid, Trotta, 1989, pp. 356-357.

37 Massimo La Torre, "Derecho y conceptos de Derecho. Tendencias evolutivas desde una perspectiva europea", cit.

38 Derecho y Razón..., Cpt. 13 y especialmente Epígrafes 57 y 58 
conforme es, sino que abarca, al mismo tiempo, un "modelo ideal": el proyecto de Derecho inscrito en la Constitución, que actúa de referente crítico. Teoría jurídica y análisis dogmático -si es que este término sigue conviniendo a una teoría que ha dejado de plegarse sobre sí misma, renunciando a las viejas aspiraciones de "complitud", coherencia y sistematicidad - participan, pues, de una doble dimensión que ha acabado por fusionarse: descriptiva del ser del derecho, y prescriptiva en lo que tiene de juicio de conformidad con la justicia rematerializada del texto constitucional ${ }^{39}$.

Si empleamos la terminología anglosajona utilizada por un autor alemán, podríamos concluir afirmando que el Derecho Constitucional se nos aparece hoy como situado a medio camino entre un vaporoso higher law, de resonancias medievales, y un rastrero (por contingente e incondicionado) statutory law tan arcaico como el anterior ${ }^{40}$. Las disposiciones constitucionales son así el fundamento de todo el derecho, pero también representan la cima del espacio jurídico, salvedad hecha de los casos en que la propia Constitución, como sucede en España, alarga tal espacio con remisiones a un Derecho Internacional que está experimentando, en materia de defensa de los derechos, transformaciones semejantes a las ya consumadas en el ámbito del Derecho Constitucional $^{41}$.

\section{Justicia constitucional e interpretación de la Constitución}

Pocas afirmaciones despiertan entre nosotros un acuerdo tan generalizado como la que se refiere a la interpretación de la Constitución como el problema, por antonomasia, de la teoría y el Derecho constitucionales de nuestros días. En Europa

\footnotetext{
39 Ferrajoli, La cultura giuridica nell'Italia del Novecento, Roma-Bari, Laterza, 1999, Cpt. IV ("La filosofia analitica e il paradigma costituzionale della scienza giuridica").

40 E. Denninger, "Constitutional Law between Statutory Law and Higher Law", en A. Pizzorusso (ed.), Law in the Making. A Comparative Survey, Berlín, Springer-Verlag, 1988, pp. 103 y ss.

41 Remito de nuevo a Ferrajoli, La sovranità nel mondo moderno, Milán, Anabasi, 1995, así como a Danilo Zolo, Cosmopolis. La prospettiva del governo mundiale, Milán, Feltrinelli, 1995.
} 
y, desde luego, en España, el Derecho Constitucional no hace mucho tiempo que disfruta de las ventajas que, para la dignidad científica de dicha rama del derecho como disciplina académica, se derivan de la judicialización de sus enunciados. Pero, una vez descubierta la terra ignota del laboratorio judicial, una vez sobrepasadas las horas que alguien llamó "de pavorosa soledad" de los cultivadores de un Derecho que, por marcar distancias con el pasado, cambió hasta el nombre, parece como si, más allá del juicio de constitucionalidad, no hubiera sino el vacío ${ }^{42}$.

El "entusiasmo" por la judicialización es comprensible, pero a veces induce a sostener tesis, desde mi punto de vista, erróneas. Por ejemplo, no creo que el ámbito objetivo del Derecho Constitucional pueda delimitarse, como a veces se hace, mediante la exclusiva referencia a los mandatos constitucionales y a la interpretación de los mismos verificada por la jurisprudencia constitucional. Se trata de un empeño que suele inscribirse dentro del contexto de un discurso sobre las fuentes de nuestra disciplina, y donde el "pie forzado" del enfoque (la tesis formalista/ tradicional de las fuentes, con la jurisprudencia como fuente auxiliar) obliga a marcar distancias, removiendo las aguas, más estancadas que turbulentas, de la hidráulica jurídica.

Bromas aparte, hoy no son pocos los autores que denuncian la "hiper-formalización" producida en nuestro pujante Derecho

42 Lo de las "horas de pavorosa soledad" está tomado de una recensión de Lorenzo Martín Retortillo, publicada en 1981, que contiene un irónico alegato contra el oportunismo que, creía él, se avecinaba: "hace Derecho Constitucional quien hace Derecho Constitucional, siempre que haga Derecho Constitucional. Lo malo sería confundir la ciencia con la longaniza y alardear de científico con la mira puesta, en cambio, en el banquete. Porque, al igual que en los bodegones barrocos se acumulan y arraciman frutos y más frutos y aun piezas de caza, hoy en el ámbito del Derecho Constitucional se ofrece, atractivo y sugeridor, un panorama, auténtica tierra de promisión, henchido de incienso y oro - tal vez sólo de plata - con el sueño de la lluvia de asuntos, de pleitos - ya hay un Tribunal Constitucional funcionando - y de dictámenes (...). Porque el hacer ciencia está, y ha estado abierto, a todos; todos los que quisieron pudieron empujar en esta a veces lenta, tan desasistida, tan desvencijada, en ocasiones, carreta de la ciencia del Derecho Constitucional, que conoció horas de pavorosa soledad". El libro recensionado era el Derecho Presupuestario, de Laband, en la edición al cuidado, y con un excelente estudio introductorio, de Álvaro Rodríguez Bereijo; cfr. Revista de Administración Pública, 96 (1981), pp. 439 y ss. 
Constitucional como consecuencia de una "estrategia de exclusiones", que tendía a deslegitimar cualquier enfoque no apegado a la cita jurisprudencial. Transcurridos ya los tiempos en los que todo estaba por hacer en materia ordinamental (fuentes, cauces de garantía, relaciones entre los subsistemas estatal y autonómico, etc.), y superada la proclividad al anatema, quizá estamos asistiendo a un movimiento pendular que reclama de los especialistas una mayor dedicación al trasfondo político de las normas, y al engarce de éstas con la realidad ${ }^{43}$.

La fascinación por la justicia constitucional induce también a cierta desmesura cuando, hablando en términos generales, se hace de ella una exigencia ineluctable para la salvaguarda de la supremacía constitucional y aun de la propia democracia. Se olvida así que la jurisdicción constitucional fue un expediente introducido en Europa en circunstancias bien concretas, las de unas democracias amenazadas, y en las que la defensa de la Constitución se planteó como un problema acuciante. Podría así decirse que en Europa la quiebra de la democracia ha actuado históricamente como un acicate para la incorporación y difusión de la justicia constitucional ${ }^{44}$. Mientras que, a la inversa, la ausencia de ésta en sistemas democráticos bien consolidados, no

43 En este sentido, he leído últimamente dos opiniones muy autorizadas, la de Luis López Guerra, en su Proyecto para el acceso a una cátedra en la Universidad Carlos III (“la tarea que se muestra en estos momentos más necesitada de atención de los especialistas del Derecho Constitucional es el análisis, exposición y clarificación de cuáles sean los contenidos materiales de las normas constitucionales, en relación con su significado político, en cuanto opciones concretas entre diversas alternativas presentes", y la de Oscar Alzaga en la "Razón de ser", escrita a modo de exordio del n 1 de la Revista, de expresivo título, Teoría y Realidad constitucional ("Creemos poco fructíferos los enfoques evasivos, por mucho que se cubran con ropajes aparentemente ricos y brillantes, y entendemos que hasta el profesor más seducido por la estética y el sex appeal del formalismo acabará encontrando fascinante el difícil mundo de las relaciones entre la Constitución, en concreto, y las normas políticas, en general, con la realidad. Nuestro sentido del olfato, vieja y fiable fuente de conocimientos, nos dice que de la conexión entre teoría y realidad podemos esperar un nuevo y fuerte impulso de nuestra Ciencia").

44 Cfr. Francisco Rubio Llorente, "Seis tesis sobre la jurisdicción constitucional en Europa", Revista Española de Derecho Constitucional, 35 (1992), pp. 9 y ss.; más recientemente, abunda en la misma idea Luis López Guerra en su "Introducción" a la selección jurisprudencial 
es un rasgo deficitario de los mismos, sino sencillamente indicio de una evolución hacia la democracia carente de sobresaltos.

En los últimos tiempos, el debate filosófico-político registra también algunas objeciones frente a la importancia cobrada por la justicia constitucional. Una muestra significativa es el influyente libro de Habermas, Faktizität und Geltung, cuyo Capítulo 6 versa sobre las relaciones entre la jurisdicción y la legislación y, más precisamente, sobre la "función y legitimidad de la jurisprudencia constitucional". Habermas parte de las ideas de Dworkin relativas a los derechos y la decisión judicial, que examina en el Capítulo 5 ("Indeterminación del Derecho y racionalidad de la jurisdicción”), confrontándolas con la posición de autores alemanes (Denninger, Maus y Böckenförde, sobre todo) y norteamericanos (Sunstein, Perry, Brest, Ackerman y Ely, entre otros). Si he comprendido bien el punto de vista de Habermas, éste resalta los riesgos que, para la certeza del derecho, se derivan del excesivo peso de una jurisprudencia "creadora" y dimanante de un Tribunal que tiende a ocupar el puesto reservado, según la lógica de la división de poderes, al legislador democrático ${ }^{45}$. Habermas simpatiza con las tesis preconizadas por Ely, contrarias al "paternalismo" del Tribunal Supremo, y defensoras de una función de éste meramente garantista/procedimental:

"El discurso jurídico - dice Habermas - puede disfrutar de una presunción de racionalidad relativamente alta, debido a que está especializado en cuestiones concernientes a la aplicación de las normas, y se beneficia además de una forma de institucionalización que resalta su condición de tercero imparcial entre las partes en causa. Pero precisamente por ello el discurso jurídico no puede sustituir al discurso politico, que es el que tiene que aportar su razón

Ilevada a cabo por él, bajo el título Las sentencias básicas del Tribunal Constitucional, Madrid, BOE/CEPC, 1998.

45 Jürgen Habermas, Fatti e Norme. Contributi a una teoria discorsiva del diritto e della democrazia, Milán, Guerini, 1996, p. 301. 
de ser a las normas y a los programas de acción, previo un debate en el que tengan oportunidad de intervenir todas las partes interesadas" 46 .

Consecuente con esa reivindicación de lo político, Habermas se apoya en construcciones del alemán Denninger y del norteamericano Sunstein, para calificar como la más importante de las funciones de la justicia constitucional la de actuar como un guardián de la democracia deliberativa ${ }^{47}$. Del primer autor citado toma la idea de los "conceptos-clave del Derecho Constitucional", es decir aquellos de los que se sirve habitualmente la jurisdicción constitucional, y que se corresponden con las transformaciones experimentadas por los derechos fundamentales en el Estado democrático: desde su condición de derechos subjetivos o de defensa frente al Estado, a su estatuto como principios objetivos del ordenamiento con proyección sobre el conjunto de éste ${ }^{48}$. Tales conceptos-clave, utilizados rutinariamente por la jurisdicción constitucional son, entre otros, el principio de proporcionalidad, el de razonabilidad, la recíproca limitación de los derechos y el juicio de ponderación, la unidad de la Constitución, etc. ${ }^{49}$.

46 Fatti e norme..., p. 316. Abunda en ideas semejantes el reciente libro de Mark Tushnet, de expresivo título, Taking the Constitution away from the Courts, Princeton, Princeton University Press, 1999.

47 Categoría, como es sabido, central en el pensamiento de Habermas. En español, pueden verse recientemente sus escritos agrupados bajo el epígrafe “¿Qué significa política deliberativa?", en Habermas, La inclusión del otro. Estudios de teoría política, Barcelona, Paidós, 1999, así como la excelente visión de conjunto sobre el pensamiento habermasiano de Fernando Vallespín, “Habermas en doce mil palabras”, Claves de razón práctica, 114 (2001), pp. 53 y ss.

48 Cfr. Peter Häberle, "Recientes desarrollos sobre derechos fundamentales en Alemania", cit., pp. 149 y ss.

49 Erhard Denninger, "Verfassungsrechtliche Schlüselbegiffe", en Der gebändigte Leviathan, Baden-Baden, 1990; cfr. Habermas, Fatti e norme..., pp. 292 y ss. De entre la abundantísima bibliografía dedicada al análisis de tales conceptos, cabe destacar el excelente número monográfico (el 5, de 1998), que dedicó al principio de proporcionalidad la revista Cuadernos de Derecho Público; también, por lo que se refiere a la ponderación, la monografía (de engañoso título) de José María Rodríguez Santiago, La ponderación de bienes e intereses en el Derecho 
De Sunstein, por su parte, toma Habermas una categoría próxima a la de los conceptos-clave, llamada por el autor norteamericano background norms. Se trata de una serie de principios inspiradores, que son propugnados como guía de conducta o, más bien, cánones de autocontención, que los Tribunales deberían seguir, con el fin de lograr el mayor consenso posible en materia de interpretación jurídica (y no sólo constitucional). Con tal propósito se enuncian una serie de postulados que ahora no voy a reproducir, pero que, en sustancia, se inspiran en el común objetivo de lograr que el debate político no salga de los cauces en los que debería desarrollarse y, subsidiariamente, en el de sugerir argumentos para el debate, garantizando, eso sí, una sustancial igualdad de oportunidades políticas para la defensa de las diferentes perspectivas ${ }^{50}$.

Con posterioridad a la aparición del libro de Habermas, el propio Sunstein ha expuesto su pensamiento al respecto, de manera más profunda y sistemática, en su brillante ensayo sobre las relaciones entre conflicto político y razonamiento jurídico ${ }^{51}$. La tesis básica del libro es que un sistema jurídico que funcione de modo mínimamente satisfactorio debe tener como objetivo generar estabilidad y consenso, en el contexto de elevadas dosis de desacuerdo político y pluralismo. A tal efecto, los Tribunales - y sobre todo aquellos con capacidad decisoria de carácter último - deben, al decir de Sunstein, operar por medio de lo que él llama (algo así como) "acuerdos teóricos no desarrollados exhaustivamente" (Incompletely Theorized Arguments). Tales argumentos permiten razonar desde un nivel de abstracción lo suficientemente elevado como para suscitar un acuerdo generalizado sobre las posiciones de principio, que podría romperse

Administrativo, Madrid, Marcial Pons, 2000. Y sobre el juicio de razonabilidad, Gino Scaccia, Gli "strumenti" della ragionevolezza nel giudizio costituzionale, Milán, Giuffrè, 2000.

50 C.R. Sunstein, After the Rights Revolution, Cambridge, 1990, pp. 170 y ss.; cfr. Habermas, Fatti e norme, cit., pp. 299-301, y 328-329.

51 C. R. Sunstein, Legal Reasoning and Political Conflict, Nueva York, Oxford University Press, 1996. 
si la lógica argumentativa descendiera hasta las minucias de detalle del caso concreto. En diversos lugares de su libro, Sunstein insiste, por ello, en lo eficaz que resulta un "uso constructivo del silencio" por parte de los Tribunales, así como en el valor del razonamiento analógico para la resolución de los casos de Derecho Constitucional ${ }^{52}$.

Si se acepta la idea, por otra parte bien difícil de rechazar, de que un derecho por principios conlleva elevadas dosis de creación en el momento de ser interpretado, entonces lo que los autores citados (y con ellos Habermas) dicen es simplemente que el responsable de la interpretación necesita una justificación externa. Ahora bien, decidir cuál sea esa justificación y enunciar, sobre la base de ella, unos determinados modelos de comportamiento, ya es cosa que entra en el terreno de la prescripción, por más que el pretexto de la misma sea uno de tanto fuste como la defensa del legislador democrático. En una dirección semejante, también Rawls otorga a la justicia constitucional nada menos que el estatuto de paradigma de la razón pública ("en un régimen constitucional con revisión judicial de la constitucionalidad de las leyes, la razón pública no es otra cosa que la razón de su Tribunal Supremo"), pero en un contexto de vigorosa defensa de la separación de poderes:

"La Constitución -añade Rawls algunas páginas más adelante- no es lo que el Tribunal dice que es, sino aquello que, sobre ella, le permiten decir quienes actúan de conformidad con la Constitución en las otras ramas del Gobierno"53

Bien están los wishful thinkings, estemos o no de acuerdo con ellos, pero lo cierto es que las dimensiones cobradas por la

\footnotetext{
52 Legal Reasoning ..., Capítulos II ("Incompletely Theorized Arguments") y III ("Analogical Reasoning"). El recurso a los I.T.A., en el momento de la elaboración de la Constitución, viene desarrollado por el propio Sunstein en su trabajo "Constitutional Agreement Without Constitutional Theories", Ratio luris, 13 (2000), pp. 117 y ss. Sobre el uso de la analogía en Derecho Constitucional, cfr. también la obra de Victor Ferreres Comella, Justicia Constitucional y Democracia, Madrid, Centro de Estudios Constitucionales, 1997.

53 J. Rawls, Political Liberalism, Nueva York, Columbia University Press, 1993, pp. 231 y 237 y, en general, Lecture VI ("The Idea of Public Reason").
} 
justicia constitucional otorgan al constitucionalismo de nuestros días un sesgo por completo inédito. La imagen kelseniana del legislador negativo resulta inadecuada para dar cuenta de una realidad en la que la jurisprudencia constitucional se ha convertido en fuente positiva de criterios interpretativos de alcance general y vinculante (artículo 5 LOPJ, por lo que se refiere a España). Lo que ha cambiado, quizá, no es tanto la función de la justicia constitucional, que continúa siendo, como en el debate clásico, defensiva de la Constitución, como la manera (por así decir rutinaria) en que tal defensa se realiza, así como la transformación de lo que la misma exige.

Por decirlo más claramente: mientras que la imagen clásica del legislador negativo tiene como presupuesto la defensa de la norma fundamental frente a la ley, mediante un juicio abstracto de compatibilidad entre ambas normas cerradas, la visón contemporánea de la justicia constitucional presupone una Constitución abierta, unos enunciados que no se prestan a formas silogísticas de enjuiciamiento, y un orden constitucional que se va creando y recreando mediante la actuación conforme a aquélla de los ciudadanos y de los poderes públicos, incluido el Tribunal Constitucional.

Las tensiones entre el legislador y la jurisdicción constitucional se convierten así en un componente inevitable de nuestras democracias, un fenómeno inherente a las mismas y frente al cual, como se ha dicho, la marcha atrás parece imposible ${ }^{54}$. Con el fin de mantener dicha tensión dentro de márgenes que no hagan de ella un mal endémico o una rémora insostenible para el funcionamiento del sistema - cosa que, por el momento, no se ve que esté en trance de ocurrir en ningún lado, pese a las protestas y denuncias de usurpación llevadas a cabo por algunos destacados originalistas norteamericanos ${ }^{55}$ - se han

\footnotetext{
54 Cfr. las "Conclusiones generales", a cargo de Eliseo Aja y Markus González Beilfuss, a la obra colectiva, coordinada por el primero, Las tensiones entre el Tribunal Constitucional y el Legislador en la Europa actual, Barcelona, Ariel, 1998.

55 Me refiero, sobre todo, a Robert Bork y a su irritada obra, The Tempting of America. The Political Seduction of the Law, cit. nota 162, especialmente Cpt.18 ("Effects for the Future").
} 
sugerido medidas "de ingeniería constitucional" dirigidas a instaurar mecanismos de cooperación entre las dos instituciones. Presupuesto para la adopción de las mismas, es "abandonar viejos tabúes por ambas partes, como la crítica per se a las sentencias que contienen orientaciones para el legislador, o la creencia de los Tribunales Constitucionales de que la inercia (pereza) del legislador es algo consustancial a las Cámaras" 56.

Y desde un plano más teórico, esta especie de "Constitución de los controladores", que hoy tenemos, puede ser contemplada desde perspectivas opuestas: bien como una regresión antidemocrática, en el sentido de que esconde la politicidad radical de decisiones colectivas básicas bajo el manto de un tecnicismo constitucional cuyos entresijos sólo unos pocos están en disposición de conocer, o bien como el perfeccionamiento y culminación de la aspiración garantizadora/limitadora que siempre alumbró al constitucionalismo ${ }^{57}$

De lo que no cabe duda es de que el panorama "dieciochesco" de frenos y contrapesos, de cuyo correcto engranaje en la maquinaria constitucional se esperaba todo para la salvaguarda de la libertad, se ha hecho más complejo. Para unos, la virtud del Poder Judicial, en un contexto en que todo y todos somos justiciables, se ha convertido en la depositaria natural de tal esperanza ${ }^{58}$. Otros reproducen la "obsesión trinitaria", y

\footnotetext{
56 Aja y González, "Conclusiones Generales", cit. Con referencia a Italia, pueden verse consideraciones semejantes en el libro de Enzo Cheli, II Giudice delle leggi. La Corte Costituzionale nella dinamica dei poteri, Bolonia, II Mulino, 1996, pp. 64 y ss.

57 Claramente decantado por el primer polo de la alternativa se muestra Tushnet, Taking the Constitution away from the Courts, cit., mientras que un representante señero de la segunda opción es Bruce Ackerman, cuya teoría constitucional de la democracia dualista, con los "momentos constitucionales" y los de la "política normal", va acompañada de la reivindicación entusiasta del juicio de constitucionalidad, que "aparece en escena para cumplir la promesa de lo político, no para acabar con ella"; cfr, en general, sus ensayos agrupados bajo el título La política del diálogo liberal, Barcelona, Gedisa, 1999 y, especialmente, el titulado "El argumento político a favor de los tribunales constitucionales" (pp. 145 y ss.), del que he tomado la frase que resalto en negrilla.

58 Cfr. M. Troper, Pour une Théorie juridique de l'État, cit., y especialmente Cpt. XIII ("Le concept de constitutionalisme et la théorie moderne du droit"). La expresión todo y todos somos
} 
explican el nuevo estado de cosas hablando de un equilibrio inestable y polimorfo entre tres polos: el de la tecnoburocracia, el de las instituciones democrático-representativas y el del Estado ético de los controladores ${ }^{59}$. Y otros, en fin, con acusado optimismo, recurren a la imagen de la "sociedad abierta de los intérpretes constitucionales", sin numerus clausus de ellos, en claro decantamiento, entre las alternativas antes enunciadas, favorable al reforzamiento del constitucionalismo ${ }^{60}$.

La popperiana búsqueda de la verdad, a través de un proceso racional, discursivo y dialéctico, con resultados siempre aproximativos y provisionales se ha convertido en un tópico por el que la ciencia del Derecho Constitucional muestra cada vez más interés ${ }^{61}$. Quizá a ella, como al Derecho en general, siempre que éste sea concebido como público intercambio de razones, sostenido por un consenso social, y dirigido al logro de una convivencia pacífica, le cuadra al dedillo la bella imagen de la tela tejida de conjeturas. Con ella concluía el filósofo griego Jenófanes, 500 años antes de Cristo, unos versos dirigidos a demostrar que aquello que denominamos conocimiento no es sino conjetura y opinión, doxa, no episteme:

justiciables es de A. Garapon, Le gardien des promesses, París, Odile Jacob, 1996, p. 21; para la cuestión, es muy útil el trabajo de Guarnieri y Pederzoli La democrazia giudiziaria, Bolonia, II Mulino, 1997.

59 Cfr. Pier Paolo Portinaro, "Dal custode della Costituzione alla Costituzione dei custodi", en Gustavo Gozzi (ed.), Democrazia, diritti, costituzione. I fondamenti costituzionali delle democrazie contemporanee, Bolonia, II Mulino, 1997, pp. 401 y ss.

60 La referencia canónica es, naturalmente, Häberle, “La sociedad abierta de los intérpretes constitucionales. Una contribución para la interpretación pluralista y 'procesal' de la Constitución", en Retos actuales del Estado constitucional, Oñati, IVAP, 1996, pp. 15 y ss., especialmente p. 31: "Limitar la interpretación constitucional a los intérpretes estatales 'gremiales', acreditados funcional-jurídicamente, sería empobrecimiento o autoengaño. Especialmente una concepción más experimental de la ciencia del Derecho constitucional como ciencia normativa y de la realidad no puede renunciar a la fantasía y fuerza creadora de los intérpretes 'no gremiales' en el proceso de la interpretación constitucional."

61 Amplias referencias en Antonino Spadaro, Contributo per una teoria della Costituzione, cit, Capt. III ("Verità, etica pubblica e Costituzione”). 
"Los dioses no nos revelaron, desde el principio, todas las cosas a los humanos; pero en el curso del tiempo, podemos aprender indagando, y conocer mejor las cosas. Por lo que respecta a la verdad certera, nadie la conoce, ni la conocerá; ni acerca de los dioses, ni tampoco de todas las cosas de las que hablo. E incluso si por azar alguien llegase a expresar la verdad perfecta, lo desconocería:

pues todo no es más que una tela tejida de conjeturas" ${ }^{62}$.

La cita que antecede cumple perfectamente, entre los varios posibles, el cometido de ser un cómodo refugio científico, construido además bajo el amparo no de una, sino de dos autoridades (y una de ellas nada menos que presocrática) ${ }^{63}$. Con ella se siente uno inducido a concluir un recorrido en el que nos hemos demorado, quizá, más de lo conveniente. Pero dejaríamos un llamativo cabo suelto si termináramos aquí, sin haber expuesto antes nuestro punto de vista con relación a lo que hemos llamado, al comienzo del subepígrafe, el problema por antonomasia del Derecho Constitucional de nuestros días, es decir, el de cuál sea el método más apropiado para la interpretación de la Constitución.

De la yuxtaposición de ideas, quizá trilladas, y citas de autoridad con las que hemos llenado las anteriores páginas, creo que pueden inferirse cuáles son las inclinaciones metodológicas del autor de ellas. No en vano se ha parafraseado alguna vez en nuestro campo el conocido dicterio "dime lo que piensas de la justicia constitucional y te diré qué concepto de Constitución tienes" ${ }^{\circ 4}$;

62 Cit. en Karl Popper, "Acerca de las Ilamadas fuentes del conocimiento", en la recopilación de ensayos de dicho autor agrupados bajo el título En búsqueda de un mundo mejor, Barcelona, Paidós, 1994, p. 71.

63 Cfr. G.W. Bowersock, "The Art of the Footnote", The American Scholar, $52-53$ (1983/84), pp. 54 y ss. y, desde la perspectiva de artículos jurídicos, A.Austin, "Footnotes as Product Differentiation", Vanderbilt Law Review, 40 (1987), pp. 1131 y ss.

64 W. Kaegi, Die Verfassung als rechtliche Grundordnung des Staates, Zürich, 1945, p. 147, cit. en García de Enterría, La Constitución como norma y el Tribunal Constitucional, Madrid, Cívitas, 1981, p. 163. 
algo que podría también ser enunciado a la inversa o, incluso, ser transformado en "dime tu concepto de Constitución y te diré lo que opinas en materia de métodos interpretativos”. Pero, por si fuera preciso ser más explícito, procedo, al estilo forense, y en trámite de conclusiones provisionales, a mostrar mi particular tela de conjeturas al respecto.

Tengo para mí que a la interpretación de la Constitución le cuadran bien las observaciones de Isaiah Berlin sobre los límites de la teoría en las cuestiones políticas. La desconfianza hacia los intelectuales en el ámbito de la política, dice Berlin, "surge de la creencia, no del todo falsa, de que, debido al deseo de ver la vida de alguna manera simple, simétrica, ponen demasiada esperanza en los resultados beneficiosos derivados de aplicar directamente a la vida conclusiones obtenidas mediante operaciones en una esfera teórica". Y la consecuencia de ello, añade, "es que si los hechos - es decir, el comportamiento de seres humanos vivos - son reacios a tal experimento, el experimentador se molesta, e intenta cambiar los hechos para adecuarse a la teoría, lo que en la práctica significa una especie de vivisección de las sociedades hasta que se conviertan en lo que la teoría originariamente declaraba que el experimento les debería haber convertido"65.

Cámbiese "intelectuales" por "constitucionalistas", y "hechos" por "sentencias", y se tendrá una visión certera acerca de las razones de una transposición y, sobre todo, de un escepticismo que hoy comparten muchos autores. Al fin y al cabo, como ya observara Radbruch, la acumulación de investigaciones sobre el método jurídico viene a ser casi siempre indicio de una ciencia carente de salud ${ }^{66}$. De ahí que se nos antojen muy acertadas

65 Isaiah Berlin, "El juicio político", en El sentido de la realidad. Sobre las ideas y su historia, Madrid, Taurus, 1998, pp. 94-95.

66 G. Radbruch, Introduzione alla scienza del diritto, Turín, Giappichelli, 1961, p. 360. La cita completa es como sigue: "Las investigaciones relativas al método se acumulan. Del mismo modo que los hombres que se atormentan con la autoobservación son, por lo general, hombres enfermos, así ocurre también con las ciencias que tienen motivos para preocuparse por el método; el hombre sano y la ciencia sana no acostumbran a indagar demasiado sobre sí mismos". 
afirmaciones del tipo "el método se hace, no se dice", o bien "del hecho (ex scripto) nace el método (ratio scientia iuris)". Dicho con otras palabras: lo interesante no es la ortodoxia interpretativa abstracta e ideal, sino la concreta (y operativa) orto-praxis constatada. El estudio del método sólo puede ser así un estudio sobre algunas constantes de la praxis ${ }^{67}$.

En esa línea, un trabajo pionero, centrado en el Derecho privado, pero convertido en obra de referencia, descalifica en sus páginas iniciales los empeños teóricos construidos more geometrico: "toda teoría que, renunciando a investigar el fenómeno mismo, hace declaraciones autoritarias e inmediatas sobre su naturaleza y contenido, debe quedar científicamente descalificada, cualesquiera que sean los intereses especulativos que en ello jueguen"68. La lectura del libro de Esser es muy recomendable para darse cuenta de que el constitucionalismo de nuestros días, al menos por lo que a la interpretación respecta, poca cosa puede descubrir que no sea un "mediterráneo". Especialmente el Capítulo V ("Importancia de los principios constitucionales positivos para la creación jurisprudencial") explica con agudeza los ingredientes de libertad y vinculación que concurren en cualquier aplicación jurisprudencial del Derecho y paradigmáticamente del Derecho Constitucional. Esser toma como ejemplo el principio de igualdad, comparando la posición del juez con la de un observador que, desde la "ventana" de la norma, dirige su mirada hacia los valores sociales admitidos, y hacia el proceso de sedimentación de los mismos "en una conciencia cultural que se apoya en la tradición, pero sujeta a un proceso de renovación constante". De dicha conciencia cultural forma parte la conciencia jurídica, que agrupa, a su vez, la doctrina y el cuerpo de precedentes jurisprudenciales, cuyo decurso evolutivo por

67 Cfr. A. Spadaro, “Ex facto (id est: ex scripto) oritur ratio scientiae iuris (Notarella sul metodo 'relazionista' nel diritto costituzionale)", en VV.AA., II metodo nella scienza del Diritto Costituzionale, Padua, CEDAM, 1997, pp. 157 y ss.

68 Josef Esser, Principio y norma en la elaboración jurisprudencial del Derecho privado, BarceIona, Bosch, 1961, p. 17. 
la vía de una argumentación sin cortes bruscos ni saltos en el vacío, es la mejor garantía contra cualquier tentación de libre recherche por parte del juez ${ }^{69}$.

Consideraciones semejantes en torno a la pervasive authority del precedente pueden hallarse también en la obra (más actual que la de Esser) de Orrù, dedicada al derecho jurisprudencial. El autor denuncia las vindicaciones de "retorno al método jurídico" (zurück zur juristischen Methode) como nostálgicas e impractibles. Lo que se necesita, según él, es no sustraer al control crítico y a la verificación de la discusión pública las opciones valorativas del juez:

"La legitimidad democrática de las valoraciones realizadas por el juez dependen de la transparencia de sus opciones axiológicas, porque cuando las mismas no son explícitas no pueden ser criticadas ni sometidas siquiera a verificación pública"70.

Si la interpretación supone al propio tiempo un acto de creación jurídica no predeterminado por la norma en todos sus extremos, como afirmaba ya prudentemente la Teoría Pura del Derecho, entonces el acto de voluntad del juez - ordinario o constitucional - tiene que cuajar en una decisión responsable. La resposiveness de la decisión judicial es la que permite paliar el llamado déficit de legitimidad de la jurisdicción en el Estado democrático. En el caso del juez ordinario, porque el eslabón que le une a la soberanía popular mediante la sumisión a la ley es un eslabón quebradizo, como bien lo acredita, con manifiesto realismo, la sujeción adicional del juez a las pautas interpretativas de la justicia constitucional, establecida en nuestra LOPJ $^{71}$. Y en

\footnotetext{
69 Esser, Principio y norma..., pp. 104-108.

70 Giovanni Orrù, Richterrecht. II problema della libertà e autorità giudiziale nella dottrina tedesca contemporanea, Milán, Giuffrè, 1988, p. 17 y, en general, Cpt. III ("Richterrecht e problematica costituzionale").

71 Cfr., in extenso, la reciente recopilación de trabajos de Luis López Guerra, agrupados bajo el título El Poder Judicial en el Estado Constitucional, Lima, Palestra editores, 2001, y especialmente el Cpt. II ("La legitimidad democrática del juez").
} 
el caso del juez constitucional, con más motivo, porque al decidir se apodera de la Constitución, por lo menos provisionalmente, en la medida en que a él le corresponde establecer, con carácter vinculante, y sin ulterior recurso, el significado de la misma.

Según una opinión muy difundida, lo que distingue la decisión política de la decisión judicial es precisamente su diferente modo de justificación y argumentación: desde los objetivos que persigue, la primera; desde la sumisión a una norma previa y la explicitación de la regla utilizada para aplicarla, la segunda ${ }^{72}$. Todo ello es sobradamente conocido. Si lo recordamos, es simplemente para destacar la importancia cobrada en las teorías de la interpretación de nuestros días (lo que es tanto como decir en la actual teoría constitucional) por la racionalidad hermenéutica de la decisión y por la disposición hacia la crítica de los autores de ella.

La gran aporía de las doctrinas postpositivistas de la interpretación constitucional es que cuanto más complejas y detalladas se hacen, llevadas por el deseo de vincular la labor del juez, más ensanchan la discrecionalidad por cuyos márgenes puede moverse cómodamente el intérprete. Bien saben esto los autores de repertorios de principios para la interpretación constitucional, quienes acostumbran a establecer ciertas reservas sobre la utilidad de los mismos. Así ocurre en el trabajo de Hesse sobre la interpretación constitucional, publicado en 1966 como Capítulo II de sus Grunzüge, en el que la admirable precisión con la que es descrita la labor de concreción constitucional, culmina (párrafo n ${ }^{\circ} 76$ ) con unas consideraciones sobre lo aproximativo del empeño:

"Cierto que la decisión jurídica, y muy en particular en el Derecho Constitucional, nunca puede ser racionalizada totalmente; pero ello sólo puede significar que de lo que se trata es de la racionalidad posible, no que sencillamente

\footnotetext{
72 Creo que un criterio semejante es el propuesto por Martin Kriele, aunque mi particular conocimiento del mismo procede de Ignacio de Otto, que lo utilizó en bastantes de sus escritos; cfr., por ejemplo, “La sujeción del juez al ordenamiento jurídico”, en Estudios sobre el Poder Judicial, Madrid, Ministerio de Justicia, 1989, pp. 66 y ss.
} 
se pueda prescindir de una metodología consciente. La 'corrección' de los resultados obtenidos a través del proceso expuesto de concretización de las normas constitucionales no tiene, por ello, el carácter de lo exactamente demostrable que puede darse en las ciencias de la Naturaleza; en el ámbito de la interpretación jurídica ello nunca pasaría de ser la ficción y la perpetua mentira de los juristas tras de la cual, y de una forma implícita e incontrolada, se ocultarían los verdaderos motivos de la decisión o esta última sería sencillamente ocultada"73.

También Böckenförde, en un Estudio expuesto por vez primera en 1975, y que lleva el significativo título "Los métodos de la interpretación constitucional. Inventario y crítica", finaliza su recorrido con la (decepcionante) conclusión de que "todos los métodos interpretativos producen como resultado, en definitiva (...), la degradación de la normatividad de la Constitución"74. Una consecuencia, desde luego, indeseable y que procede, según el autor germano, de un error en el punto de mira. Más que depuraciones metodológicas, lo que se precisa es asentar cierto consenso argumentativo, cimentado sobre un concepto de Constitución y sobre una teoría constitucional capaces de "consignar puntos de vista orientadores y estructuras fundadas en ellos para la interpretación”. En ese sentido, se pregunta el autor germano si la pretensión indiscriminada de vigencia normativa de todas y cada una de las partes de la Constitución (consecuencia de la atribución a la misma de lo que él llama la función de ley), no debería dejar paso a la idea de ordenamiento marco - una idea, por cierto, a la que nuestro TC se ha mostrado bien adepto - y a la distinción entre diferentes ámbitos de regulación de la norma constitucional.

Asímismo plantea Böckenförde - y esto es lo que más nos interesa - si no habrá llegado la hora de extraer las consecuencias

\footnotetext{
73 Konrad Hesse, Escritos de Derecho Constitucional, Madrid, Centro de Estudios Constitucionales, 1983, p. 51.

74 E.W.Böckenförde, "Los métodos de la interpretación constitucional. Inventario y crítica", en Escritos sobre derechos fundamentales, Baden-Baden, Nomos Verlagsgesellschaft, 1993, p. 37.
} 
pertinentes del doble carácter del Tribunal Constitucional, como intérprete cuya labor es mesurable a la luz de la hermenéutica judicial, y como órgano constitucional. Desde este último punto de vista, la determinación de los cometidos de la jurisdicción constitucional hay que buscarla en "la competencia atribuida y en su inserción en el orden de competencias articulante de poderes de la Constitución" (subrayado de E.B.) ${ }^{75}$.

El argumento de Bökenförde es quizá un poco confuso, sobre todo expuesto así en forma mutilada y fragmentaria, pero creo que acierta a resaltar el punto crucial de la cuestión. La mejor garantía de que la interpretación de la Constitución realizada con carácter determinante por el intérprete último no será la burda imposición de la voluntad de unos cuantos jueces con intereses inconfesables, sino el resultado de una operación realizada con arreglo a una técnica jurídica generalmente aceptada, es una de tipo estructural. O, mejor dicho, no una, sino varias razones de tipo estructural.

En el orden interno, es decir en el proceso decisorio, la argumentación del juez constitucional sustituye la condición restrictiva de la vinculación a la ley, presente en la argumentación del juez ordinario, por la vinculación a una norma, la Constitución, plagada de disposiciones abstractas, abiertas y con intensa carga ideológica. Pero su argumentación comparte con la del juez ordinario otras condiciones restrictivas, como son la vinculación al precedente y a la dogmática. Especialmente el precedente, como ya lo hemos dicho a propósito de la tesis de Esser, tiene una fuerza general que resulta de dos reglas áureas:

(1) Si puede aducirse un precedente en favor o en contra de una decisión, hay que aducirlo.

(2) Quien quiera apartase de un precedente, corre con la carga de la argumentación ${ }^{76}$.

\footnotetext{
75 "Los métodos de la interpretación constitucional...", pp. 40-42.

76 Robert Alexy, Theorie der juristischen Argumentation, p. 339, en auto-cita del propio Alexy, Teoría de los derechos fundamentales, Madrid, Centro de Estudios Constitucionales, 1993,
} 
El voto particular del magistrado Rodríguez Bereijo en la STC 222/92 (caso subrogación arrendaticia mortis causa en uniones de becho), un voto del que se ha dicho que es "una de la páginas de Derecho Constitucional más lúcidas que se han escrito en este país durante los últimos años"77, se centra precisamente en la supuesta vulneración de la segunda de dichas reglas por parte de la mayoría del Tribunal:

"No se trata, claro está, de 'sacralizar' el respeto a la jurisprudencia constitucional, de modo que resulte imposible su cambio o modificación. Ello conduciría a una petrificación, a todas luces indeseable, de nuestra interpretación constitucional. Es, pues, no sólo legítima, sino también saludable, una evolución progresiva en la interpretación constitucional. Pero ello debe hacerse, además de con la necesaria prudencia y equilibrio, siempre de manera explícita y razonada, (...) para no generar incertidumbre e inseguridad jurídica respecto del sentido y alcance de la interpretación constitucional que a este Tribunal compete. Si los cambios u oscilaciones bruscos en toda jurisprudencia son siempre peligrosos, lo son mucho más cuando de la jurisprudencia constitucional se trata".

Se dirá que el consenso argumentativo, reclamado por Böckenförde en su artículo sobre los métodos de interpretación, fue vulnerado en el caso recién aducido. Pero ahí está el voto particular para establecer la crítica, y ahí está la doctrina, libre de las restricciones consustanciales a la decisión judicial, para airear la denuncia y reclamar contención. La justicia constitucional es siempre justicia que se administra de forma colegiada y siguiendo reglas estrictas de formación de voluntad, que pueden ser, por sí solas, una garantía de "elección racional". A falta de trabajos que profundicen en ese aspecto de la cuestión, al estilo

p. 537. Cfr. también las consideraciones, muy parecidas, de Sunstein ("Much of the discipline on judges comes not from constitutional text and history, but from past cases ..."), Legal Reasoning and Political Conflict, cit., pp. 180 y ss.

77 Ángel Garrorena, en la "Encuesta sobre la orientación actual del Derecho Constitucional", Teoría y Realidad Constitucional, 1 (1998), p. 43. 
norteamericano ${ }^{78}$, lo que sí es seguro es que no hay decisión de la justicia constitucional que no sea "mirada con lupa" por los teóricos y por los demás operadores jurídicos.

El conjunto de reglas, institucionalizadas o no, en materia de argumentación, actuantes en el proceso de aplicación del Derecho, forma parte, según Alexy, de un modelo de sistema jurídico articulado en tres niveles: uno, el de las reglas; un segundo, el de los principios; y un tercero, el del procedimiento:

"Lo que hasta ahora se ha descrito, el nivel de la regla y el de los principios, no proporciona un cuadro completo del sistema jurídico. Ni los principios ni las reglas regulan por sí mismos su aplicación. Ellos representan sólo el costado pasivo del sistema jurídico. Si se quiere obtener un modelo completo, hay que agregar al costado pasivo uno activo, referido al procedimiento de la aplicación de las reglas y de los principios (...). En un sistema orientado por el concepto de la razón práctica, este tercer nivel puede ser sólo el de un procedimiento que asegure la racionalidad"79.

De la misma forma que su Teoría de los derechos fundamentales nos recuerda que la Constitución no contiene sólo principios de índole material, sino también principios procedimentales (por ejemplo, entre otros muchos, el que dispone que es al legislador democrático a quien corresponde adoptar las decisiones más importantes para la comunidad $)^{80}$, Alexy entiende aquí que un

\footnotetext{
78 Vienen de inmediato a la cabeza al menos dos obras, la clásica de Woodward y Armstrong, The Brethren, Nueva York, Simon \& Schuster, 1979, que cubre el período 1969-1976, y la más reciente, de David Savage, Turning Right. The Making of the Rehnquist Supreme Court, Nueva York, John Wiley \& Sons, 1992; por no hablar de la serie de obras publicadas a raíz de la decisión del Tribunal Supremo en el asunto del recuento de los votos de Florida durante las últimas presidenciales, por ejemplo la de Alan Dershowitz, Supreme Injustice, Nueva York, Oxford University Press, 2001, o la editada por C. Sunstein y R. Epstein, The Vote: Bush, Gore and the Supreme Court, Chicago, University of Chicago Press, 2001. En 2001 vio además la luz la monumental The Supreme Court in Conference (1940-1985): the Private Discussions behind nearly 300 Supreme Court Decissions, Nueva York, Oxford University Press.

79 Alexy, "Sistema jurídico y razón práctica", en El concepto y la validez del Derecho, Barcelona, Gedisa, 1994, p. 173
}

80 Teoría de los derechos fundamentales, cit., p. 133 
sistema jurídico atrapado por la disyuntiva "modelo de reglas" versus "modelo de principios" (¿legalismo versus constitucionalismo?), sólo puede salir de semejante trampa mortal, supliendo las carencias de uno y otro modelo mediante la contribución del "tercer nivel" del sistema jurídico, el de la racionalidad práctica procedimental:

"Hay que excluir un legalismo estrictamente orientado por las reglas. Por razones de racionalidad práctica, es irrenunciable la presencia de principios y con ello - dicho con otra terminología - de valores en el sistema jurídico. En un Estado constitucional democrático, los principios tienen si no exclusivamente sí en buena parte su ubicación jurídico-positiva en la Constitución. No se pierde por ello la independencia del derecho legislado ordinario. En el modelo de tres niveles se convierte en un problema de la ponderación entre el principio formal de la competencia de decisión del legislador legitimado democráticamente y los principios materiales de la Constitución. Los resultados de esta ponderación, al igual que de otras ponderaciones, son fundamentables racionalmente" ${ }^{" 1}$.

Sobre la base de tales afirmaciones, no creo que sea exagerado decir que si el núcleo de la teoría constitucional de nuestros días es la interpretación de la Constitución, el núcleo de la interpretación de la Constitución no es otro que el del deslinde de atribuciones respectivas, en el desempeño de tal cometido, entre el legislador democrático y el juez constitucional.

Pero con ello volvemos al punto del que partíamos al inicio del epígrafe, a propósito de las observaciones de Habermas contra la invasión de la justicia constitucional. Permítasenos añadir ahora un par de consideraciones a modo de epílogo.

Una tradición jacobina y varias décadas de positivismo legalista dificultan en Europa algo que en los Estados Unidos se contempla con toda naturalidad. Me refiero a las resistencias

81 Alexy, "Sistema jurídico y razón práctica", pp. 176-177. 
que aquí levanta todavía la idea de que el juez, cualquier juez, desempeña una función política; tanto más si su cometido es interpretar la Constitución, en el seno de un Tribunal cualificado como supremo intérprete de ella y que, en su condición de órgano constitucional, forma parte (como dirían los norteamericanos) de una society's governing coalition. Entre los miembros de dicha coalición gobernante, por otro nombre "poderes del Estado", resulta consustancial a la lógica del Estado Constitucional que se produzca cierta tensión. Al fin y al cabo, si hay dos conceptos claves en el funcionamiento de tal tipo de Estado, uno de ellos es el de derechos fundamentales, pero el otro, como bien ha resaltado Aragón Reyes, es el de control, y un control deja de serlo genuinamente cuando el controlador (o quien actúa como tal, pues las funciones pueden ser intercambiables) hace de la condescendencia su guía de conducta. Otra cosa es que dicha tensión desemboque en un conflicto irresoluble y susceptible de causar, por su persistencia, un bloqueo institucional. Pero de ello la historia, al menos en un contexto democrático, ofrece contadísimos ejemplos ${ }^{82}$.

A partir de un argumento tan cargado de naïveté, quizá resulte más sencillo admitir que el legislador y el Tribunal Constitucional comparten un mismo "ámbito de diálogo", en el seno del cual cada uno conserva una capacidad de reacción que excluye monopolios de la última palabra. La labor de la justicia constitucional al enjuiciar el producto de la voluntad del legislador se parece así cada vez más a un "diálogo no coercitivo" que a menudo sugiere, más que impone, unos caminos en vez de otros, en aras de la supremacía de la Constitución ${ }^{83}$. "Nadie

82 Remito al clásico trabajo de Robert Dahl, “Decision-Making in a Democracy: the Supreme Court as a National Policy-Maker", The Journal of Public Law, 6 (1957), pp. 279 y ss., donde se demuestra la sintonía esencial, comprobable a la larga, entre los puntos de vista del Congreso y los del Tribunal Supremo. Cuando hago la salvedad del contexto democrático, estoy pensando en el caso del Perú, donde el conflicto entre el presidente Fujimori y el Tribunal Constitucional, a propósito del cómputo de los mandatos presidenciales a efectos de reelección, se resolvió, de la manera más grotesca, con la destitución de varios magistrados.

83 Tal es el argumento, a veces un poco forzado, que desarrolla Robert Burt en su trabajo "Constitutional Law and the Teaching of Parables", Yale Law Journal, 93 (1984), pp. 455 y ss. 
como el poder judicial - escribe Laurence Tribe, expresando la misma idea - se halla capacitado para, y tiene el compromiso de, desarrollar un discurso constitucional capaz de justificar y aportar razones que sustenten su opinión sobre el comportamiento de los otros poderes, mediante un diálogo con quienes leen la misma Constitución, aun cuando el punto de vista de unos y de otros pueda ser distinto" ${ }^{84}$.

Quien conceda crédito (por decirlo con Bickel) a las "virtudes pasivas" de la justicia constitucional, no verá, en definitiva, que el manido rasgo contramayoritario de ella plantee "dificultad" alguna ${ }^{85}$; y como consecuencia de ello, la afanosa búsqueda del único método interpretativo respetuoso con las esencias democráticas, fuente de tantas polémicas, pierde buena parte de sentido.

Por más que dicha postura pueda ser tildada de abandonista, parece estar abriéndose paso la idea de que el Derecho Constitucional se ba troceado en zonas normativas que exigen un tratamiento diferenciado; o, lo que viene a ser lo mismo, está emergiendo la convicción de que las grandes teorías omnicomprensivas sobre interpretación de la Constitución (teorías prescriptivas de una ortodoxia que a menudo tienen mucho de pie forzado) son incapaces de dar cuenta de una realidad constitucional poliédrica, en la que los hechos - léase las decisiones de los intérpretes - "hablan por sí solos"86.

Burt toma como paradigma el diálogo entre el Tribunal Supremo, el Congreso y la opinión pública a que dio lugar la decisión del caso Brown v. Board of Education. En la misma idea del diálogo entre el Tribunal y el Congreso insisten diferentes trabajos de Ferejohn y Weingast, una reseña de los cuales, a cargo de Pablo Salvador Coderch, puede verse en el Anuario de Derecho Civil, XLV (1992), pp. 1591 y ss.

84 Laurence Tribe, American Constitutional Law, Mineola, The Foundation Press, 1988, p. 15, y del mismo autor, junto con M. Dorf, in extenso, On Reading the Constitution, Cambridge, Harvard University Press, 1991, pp. 32 y ss.

85 Alexander Bickel, The Least Dangerous Branch. The Supreme Court at the Bar of Politics, New Haven, Yale University Press, 1986, Cpt. IV.

86 Cfr. la intervención de Cesare Pinelli, recogida en el libro II metodo nella Scienza del Diritto Costituzionale, cit., pp. 110 a 113. El autor recurre a la imagen de un glaciar que se disuelve en ríos distintos para ilustrar la fragmentación metodológica experimentada por el Derecho Constitucional. 
Analizando un fenómeno de esa naturaleza, Mark Tushnet defiende la opinión de que las "grandes teorías" interpretativas de la doctrina norteamericana tan sólo sirven si uno acepta no sobrepasar los confines propuestos, a modo de petición de principio, por cada una de ellas. Además, el mismo autor constata que lo que vale para cuestiones de libertad de expresión - digamos las teorías de Ely sobre apertura de los canales de participación y refuerzo de la representación - generalmente resulta inútil en otras “áreas”, por ejemplo, en materia de privacidad, discriminación por razón de sexo o justicia penal, donde se exigen buenas dosis de filosofía moral, al estilo Dworkin, o de originalismo, constatación que también vale a la inversa ${ }^{87}$. La conclusión del libro de Tushnet, tras más de 300 páginas de análisis minucioso, no puede ser más desalentadora:

"La tradición liberal hace de la teoría constitucional algo al mismo tiempo necesario e imposible. Necesario porque aporta el tipo de limitaciones que tal tradición prescribe para quienes mandan, ya sean legisladores o jueces. Pero imposible, porque no hay teoría constitucional capaz de satisfacer simultáneamente el doble objetivo de marcar límites a la actividad del legislador y a la del juez. Cuanto más limitaciones propugnemos para los jueces, más libre de ellas dejaremos al legislador; y cuanto más limitemos al legislador, más libertad dejaremos a los jueces para hacer lo que ellos quieran"88.

Menos mal que la teoría constitucional siempre podrá extraer de la chistera el socorrido recurso de la autocontención judicial, algo que no justifica, desde luego, las alforjas empleadas para el viaje.

La judicial self-restraint viene a ser el equivalente doctinal de la candorosa estipulación constitucional que prescribía

\footnotetext{
87 Mark Tushnet, Red, White and Blue. A Critical Analysis of Constitutional Law, Cambridge, Harvard University Press, 1988, Cpt V (“Intuitionism and Little Theory”).

88 Red, White and Blue..., p. 313.
} 
el ser justos y benéficos. Aunque su linaje no es tan antiguo como el de dicha estipulación, tampoco es desdeñable; procede, al parecer, del voto particular firmado en 1936 por el juez Stone en Butler $v$. United States, un caso hoy célebre por haber sido el detonante de la "guerra" entre el Tribunal y el presidente Roosevelt, a propósito del New Deal. Disconforme con la declaración de inconstitucionalidad de la Agricultural Adjustment Act, el juez Stone dejó escrito, en frase que ha hecho fortuna, que "the only check upon our exercise of power is our own sense of self-restraint" ${ }^{\prime 29}$. En 1924, un trabajo dedicado a la Judicial Self-Limitation sostenía ya que los jueces deberían abstenerse de dar opinión en los asuntos políticos particularmente espinosos (prickly issues) o candentes (politically hot), así como en aquellos que afectaran al hipersensitive nerve of public opinion ${ }^{90}$.

Se trata, como se ve, de formulaciones prescriptivas que poco añaden a lo que ya se infiere del principio estructural de la división de poderes, en lo que tiene de reserva en exclusiva de un núcleo intocable de funciones para cada uno de ellos. Si de prescribir se trata, no se ve la causa por la que la virtud de la contención y el fair play no deba preconizarse también con respecto a los titulares de los órganos político-representativos. Por ejemplo para evitar que, como ha sucedido entre nosotros varias veces, la dinámica del Estado de partidos produzca el efecto de bloquear contra legem, y más allá de todo plazo razonable, la renovación del Tribunal Constitucional.

Como escribió Cappelletti en su clásico trabajo sobre los jueces-legisladores, el buen juez no es el juez contenido, sino aquel que, consciente de la grandeza y de las debilidades de la función que desempeña, es capaz de discernir si las circunstancias del caso aconsejan ser cauteloso o audaz, desplegando, en

89 Butler v. U.S., 297 U.S., 1, 34; para el contexto del caso, cfr. Laurence Tribe, God Save this Honorable Court. How the Choices of Supreme Court Justices Shapes our History, Nueva York, Penguin, 1986, pp. 80-82.

90 M. Finkelstein, “Judicial Self-Limitation”, Harvard Law Review, 338 (1924), pp. 344 y ss. 
consecuencia, de manera convincente, los argumentos jurídicos que procedan ${ }^{91}$.

Bien sé que anular disposiciones de una ley - no una ley, como se suele decir siempre, y muy raras veces, que yo sepa, ocurre - no es cuestión baladí. También soy consciente de que el carácter de la Constitución como norma-marco conlleva exigencias muy concretas dirigidas a salvaguardar el producto de la voluntas legislatoris. Por lo demás, nadie como el ex-presidente del Tribunal, Tomás y Valiente, supo defender con tanto énfasis, en decisiones por él firmadas como juez constitucional, y en exposiciones públicas, el valor de la autocontención ${ }^{92}$. Pero lo que no logra convencerme es el intento de elevar la self-restraint de la jurisdicción constitucional a la condición de principio o criterio marco para la interpretación constitucional.

Dicho intento aparece en un trabajo de Antonio Troncoso, titulado "Método jurídico, interpretación constitucional y principio democrático". Aunque no ha lugar a reproducir aquí en todos sus extremos una controversia que viene facilitada por nuestro trato asiduo como miembros del mismo claustro universitario, la tesis básica de dicho trabajo es que la eficacia jurídica del principio democrático exige autocontención judicial en la interpretación de las cláusulas generales cuando de los procedimientos de control de constitucionalidad se trata. La deferencia con el legislador debería ser así, a juicio de Troncoso, la suprema lex del juez constitucional, a menos que se encontrara ante un supuesto de incompatibilidad manifiesta entre la Constitución y el texto enjuiciado, o bien cuando el parámetro de juicio no fuera una cláusula general, sino una cláusula cerrada o, con otros términos, una regla constitucional’3.

\footnotetext{
91 Mauro Cappelletti, Giudici legislatori?, Milán, Giuffrè, 1984, p. 82

92 Ejemplo de lo primero puede ser su voto particular a la STC 53/1985 (caso despenalización del aborto), y de lo segundo muchos de sus artículos y conferencias; como muestra puede verse el titulado "Juzgar, arbitrar, legislar", recogido en A orillas del Estado, Madrid, Taurus, 1996, pp. 25 y ss., donde Tomás y Valiente deja constancia de que la autorrestricción "ha sido y es preocupación constante (del Tribunal), posibles errores al margen".
} 
Dejando de lado la dificultad (reconocida por el propio Troncoso) que entraña distinguir entre cláusulas abiertas y cerradas, y al margen de que es poco probable que se dé una contradicción manifiesta entre Constitución y ley, el problema es, una vez más, el del punto de partida. Lo que explica el resurgimiento y la generalización en nuestros días de la (llamada) "jurisdicción de la libertad" no es el "miedo al principio democrático", evocado por mi colega apelando a los tiempos de la revolución norteamericana, sino precisamente la desconfianza en el legislador.

Desde tal presupuesto se comprenden mejor las cautelas de la propia Constitución en materia de garantía de los derechos, cautelas que lo son frente al legislador: exigencia de mayoría cualificada en la reserva de ley orgánica y garantía del contenido esencial de los derechos. No hay un "núcleo menor" de contenido esencial frente al legislador y otro más exigente frente a la actividad de la Administración o la de los jueces ordinarios. El contenido esencial es uno, y es uno frente al legislador, quien encuentra precisamente ahí el límite infranqueable al contenido legal por él estatuido. Y a quien corresponde razonar si tal límite ha sido o no respetado, es al Tribunal Constitucional.

En último extremo se trata no de una cuestión de conceptos, sino de concepciones. La cualidad, y la calidad, democrática no es hoy mensurable según el simple criterio del "respeto a la voluntad de la mayoría", sino con arreglo a los cánones "respeto de las minorías" y, sobre todo, "garantías de los derechos". Entre otras cosas, porque lo primero es retórica huera si falta lo segundo. La voluntad de la mayoría se forma sobre la base de la celebración periódica, y con las debidas garantías, de elecciones libres y competitivas. De ellas surge un legislador plural, tanto más plural cuanto más genuinamente política sea la división territorial del poder. La idea de una voluntad unívoca

93 Antonio Troncoso, “Método jurídico, interpretación constitucional y principio democrático", recogido en Eduardo Espín y Francisco J. Díaz Reborio (eds.), La Justicia Constitucional en el Estado Democrático, Valencia, Tirant lo Blanch, 2000, pp. 399 y ss. 
del legislador contrapuesta a la de unos jueces que nadie ba elegido resulta, en definitiva, tan burda y simplista como la del legislador proclive a vulnerar los derechos, vigilado y contenido por los guardianes de la Constitución.

Si, como la historia enseña, el constitucionalismo y la democracia han tendido a presentarse en relación conflictiva, los componentes de uno y de otro confluyen hoy en un mismo ámbito conceptual cada vez más riguroso y exigente. De cara al futuro, la universalización de lo que el constitucionalismo implica, y la generalización y profundización de lo que la democracia demanda, deberían ser, en tanto que ideales por todos compartidos, la suprema guía de conducta. 